\title{
UNA NUEVA INTERPRETACIÓN DEL PATIO DE LA CASA DE CONTRATACIÓN DEL ALCÁZAR DE SEVILLA *
}

\section{Antonio Almagro}

CSIC, Granada

\begin{abstract}
En el presente artículo se aborda una revisión del llamado patio de la casa de Contratación de Sevilla a la luz de los nuevos conocimientos que de la arquitectura andalusí nos han aportado las más recientes investigaciones. Frente a la interpretación tradicional de considerar su origen en el siglo XI y haber sufrido dos reformas de época almohade, proponemos considerar un primer momento de época almohade y sucesivas reformas cristianas, la primera de ellas posiblemente de tiempos de Pedro I, a mediados del siglo XIV, dentro de un gran programa constructivo desarrollado por el monarca castellano en el Alcázar de Sevilla.

Palabras clave: Sevilla; Alcázar; arquitectura almohade; arquitectura mudéjar.
\end{abstract}

This paper presents a review of the so called patio of the Casa de Contratación in Seville according to new data provided by recent research on the architecture of al-Andalus. Differing from traditional interpretations that supposed its origin to be in the eleventh century with two reforms in Almohad times, we propose the consideration of an initial Almohad period and successive Christian transformations, the first of which probably took place in the times of Peter the $1^{\text {st }}$, in the middle of the fourteenth century, as part as a huge construction program carried out by the Castilian monarch in the Alcazar of Seville.

Key words: Seville; Alcazar; Almohad Architecture; Mudejar Architecture.

\section{Introducción}

El patio de la Casa de Contratación, situado dentro del actual edificio que alberga la Consejería de Obras Públicas de la Junta de Andalucía, es un conjunto arquitectónico que se presenta como uno de los arquetipos de la arquitectura almohade en la Península (Figs. 1 y 2). Este patio fue sin duda el elemento articulador de uno de los diversos palacios o residencias que integraron los reales alcázares en época medieval. Desde su descubrimiento y restauración en los años setenta del pasado siglo por obra de Rafael Manzano Martos, restauración concluida por su discípulo Manuel Vigil-Escalera, ha pasado a formar

* El presente trabajo ha sido realizado en el marco del proyecto de investigación BHA2003-03983, del Plan Nacional de Investigación Científica y Desarrollo Tecnológico. 
parte del imaginario de la arquitectura andalusí sin que apenas se haya entrado a discutir algunos de los presupuestos con que hoy se nos presenta este interesante conjunto arquitectónico. Treinta años después de su descubrimiento, nuestros conocimientos de la arquitectura andalusí en general y de la sevillana en particular se han visto notablemente ampliados, especialmente en los últimos años merced, sobre todo, a las investigaciones y hallazgos arqueológicos tanto sevillanos como de otras zonas de la Península, que nos aportan nueva luz sobre distintos aspectos que aparecen en la composición y organización espacial de este patio. De manera especial hay que mencionar las más recientes excavaciones e investigaciones arqueológicas realizadas en el Alcázar que nos permiten, por primera vez, tener una referencia secuencial con información contrastada arqueológicamente y que posibilita prescindir de suposiciones de adscripción cronológica sin base material, para pasar a disponer, aunque sea de forma limitada, de algunos testimonios de datación más fidedigna.

Las circunstancias del hallazgo de las estructuras medievales de este conjunto han sido narradas de forma sucinta por Manzano ${ }^{1}$. Sabemos que el edificio que había albergado hasta el siglo XVIII la famosa institución de la Casa de Contratación, que durante más de dos siglos monopolizó las relaciones comerciales y migratorias de España con América, fue demolido a comienzo de los años sesenta del siglo $\mathrm{XX}^{2}$. Por lo que podremos vislumbrar a través de este trabajo, cabe suponer que esta edificación, fruto de numerosas trasformaciones acaecidas durante su larga vida, puede que contuviera aún partes sustanciales de las estructuras medievales que allí se levantaban y que por lo que nos dice la documentación, nunca fueron totalmente eliminadas para construir algo de nueva planta, sino que fueron objeto de múltiples y sucesivas reparaciones y trasformaciones. Esto explica, por ejemplo, que el pórtico septentrional del patio que se conforma con una espléndida composición de sebkas y arcos lobulados se haya conservado en parte sustancial, aunque según su restaurador, sus restos se recogieran del vertedero a donde fueron trasladados los escombros del derribo. Igual que estas estructuras, cuya identificación fue posible por sus marcadas formas y rasgos estilísticos, podemos presumir que acabaran en el mismo lugar otros elementos de apariencia menos significativa tras haber sido tro-

\footnotetext{
${ }^{1}$ Manzano 1995a:348-349; 1995b:122.

2 Valor 1991:107.
} 
ceados y separados de su contexto. Tampoco debían ser faltos de interés los distintos elementos de la fase más tardía del edificio, que sabemos contó con un patio porticado sostenido por columnas de mármol dispuestas en sus dos pisos ${ }^{3}$. Algún exiguo vestigio de ello ha quedado, como veremos. Es probable que el uso variado que tuvo en las dos últimas centurias hubiera deteriorado sus fábricas, pero el derribo de tan significativo edificio, al menos desde el punto de vista histórico, sin que sepamos hubiera una clara oposición a ello, sólo se comprende desde la consideración de las circunstancias del momento en que se realizó y de la propiedad del mismo.

La no muy abundante historiografía de este conjunto se reduce prácticamente al librito publicado por Manuel Vigil-Escalera ${ }^{4}$ tras la culminación de la restauración del conjunto y a los trabajos publicados por el propio Rafael Manzano ${ }^{5}$ sobre las casas, palacios y jardines andalusíes. En ellos se establece la interpretación cronológica que hasta ahora no había sido cuestionada por toda otra serie de autores que han incluido en sus trabajos este conjunto como ejemplo de la arquitectura andalusí de época abbadí y almohade ${ }^{6}$. La teoría propuesta por Manzano y mantenida por Vigil-Escalera podemos resumirla del siguiente modo.

Hubo un patio de época abbadí, identificado como parte del alcázar al-Mubarak, al que corresponderían las dos albercas rectangulares existentes frente a los pórticos y los andenes que las acompañan, con rampas de bajada en el lado norte hacia otros andenes más bajos (Fig. 6). Estos andenes delimitan áreas de jardín que pudieron estar dispuestas con forma de crucero. No se habrían conservado restos de los pórticos, aunque podría pertenecer a este período el vano tripartito de acceso al salón norte (Fig. 5).

Este patio habría sido reformado en época almohade. En un primer momento se habrían decorado los paramentos verticales de andenes y rampas con pinturas representando arcos mixtilíneos. Posteriormente el patio se modificó sustancialmente construyéndose nuevos pórticos, de los que se habrían conservado restos importantes del lado norte

${ }^{3}$ Gil-Bermejo 1973:703.

4 Vigil Escalera 1992.

5 Manzano 1995a:347-349; 1995b:118-122; 1999:73-75.

${ }^{6}$ Recientemente la adscripción abbadí de la fase más antigua ha sido cuestionada de pasada por algunos autores, sobre todo a la luz de las excavaciones llevadas a cabo en el Alcázar en los últimos años (Tabales 2001:28; Navarro 2005:122).

Al-Qanțara (AQ) XXVIII 1, enero-junio 2007, pp. 181-228 ISSN 0211-3589 
que han permitido su anastylosis. Se habrían enterrado los parterres, aunque no las albercas ${ }^{7}$ y se habría dispuesto una nueva organización de jardín con forma de crucero con los andenes conteniendo albercas dispuestas en cruz, comunicadas entre sí bajo puentecillos y a través de una alberca central circular (Fig. 12). Las albercas tienen sus paredes decoradas con ondas geométricas en las que forman cruz y con motivos vegetales dentro de arcos mixtilíneos en la central. Los nuevos parterres están situados a notable profundidad $(1,8 \mathrm{~m}$.) y cercados por muros de ladrillo con arquerías ciegas conteniendo pinturas que representan puertas (Fig. 11). Las dimensiones del patio no habrían variado en esta transformación.

Este patio habría sido nuevamente alterado en el siglo XVI por las reformas realizadas para alojar la Casa de Contratación, aunque a este período apenas se le ha prestado atención.

En un reciente artículo de M. Vigil-Escalera ${ }^{8}$, este autor vuelve a reconsiderar algunos aspectos de este patio, en especial los relativos a la forma del jardín de la primera época, llegando a la conclusión de que quizás no fuera de crucero, en base a recientes hallazgos aparecidos en la ciudad de Sevilla. En algún momento insinúa dudas en cuanto a la cronología del conjunto, pero sin llegar a plantear nuevas hipótesis.

\section{Crítica de la teoría tradicional}

Estas hipótesis plantean distintas dificultades que hoy se ven además enfatizadas por la nueva información con que contamos gracias a las investigaciones arqueológicas más recientes llevadas a cabo tanto en el Alcázar como en otros sitios de Sevilla e incluso de otros lugares. Las excavaciones recientes llevadas a cabo por M. A. Tabales ${ }^{9}$ en distintas zonas del Alcázar han puesto de manifiesto que las estructuras abbadíes del siglo XI fueron sistemáticamente destruidas, encontrándose a cotas muy inferiores a las actuales. Tal es el caso de las encontradas en el Patio de la Montería ${ }^{10}$ o en el Patio de las Doncellas ${ }^{11}$. Aun-

\footnotetext{
7 En este punto difieren las hipótesis de Manzano y Vigil-Escalera, pues mientras el primero apunta que fueron enterradas (Manzano 1995b:121), el segundo sostiene que quedó en uso al menos la septentrional (Vigil Escalera 1992:39; 2004:dibujo p. 66).

8 Vigil-Escalera 2004.

9 Tabales 2000, 2001, 2002, 2003.

10 Tabales 2000.

11 Tabales 2003a.
} 
que este extremo no ha podido ser corroborado en el área que nos ocupa, ya que en la época en que se descubrió y excavó no se aplicaba la metodología estratigráfica en estructuras medievales y era poco lo que se sabía de los materiales arqueológicos de esos períodos, no resulta aventurado suponer que la situación sería semejante a la de los otros lugares mencionados. De hecho, está plenamente comprobado que el Palacio de D. Pedro no reutilizó ninguna estructura, ni abbadí ni almohade, sino que se construyó de nueva planta sobre los restos superpuestos de ambos períodos ${ }^{12}$. Todo esto hace difícilmente asumible que hayan podido coexistir estructuras abbadíes con otras almohades, y sobre todo, que los supuestos restos del siglo XI puedan estar situados con una cota de suelos casi idéntica a la actual.

Aceptando que el pórtico norte, remontado con los restos recuperados de la escombrera, es de época almohade (Fig. 5), parece bastante lógico relacionar las estructuras del jardín más antiguas con dicho pórtico, incluyendo las pinturas que decoran los paramentos de los arriates. La situación de los pilares del pórtico en relación con los bordes del jardín parece mantener coherencia con esta hipótesis. Lo mismo cabe decir con la alberca, pese a la hipótesis apuntada por Vigil-Escalera de que este elemento sufrió una reforma al sobreelevarse el nivel del suelo para adaptarse al nivel del pórtico. Si esto fue así, esa supuesta reforma contemporánea a la construcción del pórtico afectó también a toda la estructura de andenes y rampas, pues las dos rampas de descenso hacia los andenes del supuesto jardín abbadí, desembarcan en el nivel actual del pavimento y no en otro inferior, lo que querría decir que se reformaron a la vez que la alberca. Pero aún aceptando que exista una reforma y recrecido de la alberca, eso no permite suponer que esta última sea de época abbadí y con ella todo el resto de las estructuras del jardín que aparecen en ambos extremos del patio. Los andenes, rampas, decoración pictórica y demás estructuras conservadas junto al pórtico septentrional, y éste mismo, creemos que hay que considerarlos todos pertenecientes a un único momento, el almohade, independientemente de que algunos elementos hayan podido sufrir alguna pequeña reforma. Más adelante trataremos de plantear una hipótesis sobre la forma de este jardín.

Lo que resulta más difícil de aceptar es la relación de contemporaneidad entre el pórtico mencionado del lado norte y la estructura hoy

12 Tabales 2001:27-28; 2002:288-290. En la primera de estas citas ya pone en duda la datación abbadí propuesta para las estructuras del patio de Contratación.

Al-Qanțara (AQ) XXVIII 1, enero-junio 2007, pp. 181-228 ISSN 0211-3589 
visible de crucero con los parterres más profundos. Si analizamos estas estructuras nos daremos cuenta que responden a un esquema de diseño basado en un cuadrado. Es decir, están concebidos para ocupar un espacio de planta cuadrada y no rectangular, como hoy presenta el patio y como debió ser en época almohade. Por otro lado, parece bastante inverosímil, a la vista de cuanto conocemos de los patios andalusíes, aceptar la coexistencia de unas albercas dispuestas junto a los pórticos con otra alberca extraña con forma de cruz. Máxime cuando todo apunta a que las dos albercas mencionados se han visto cercenadas por la estructura del crucero. Si la estructura del crucero que hoy vemos fuera contemporánea al pórtico almohade, lo lógico hubiera sido alargar los andenes, albercas y parterres hasta la proximidad de aquél, y no dejar un espacio, bien fuera vacío o con una pequeña alberca a la que además se la reducía caprichosamente de proporción. Una disposición de tal tipo, aparte de carecer de paralelo alguno en la arquitectura andalusí, creemos que carece de toda lógica. Esto nos lleva a pensar que dicha estructura de crucero es el fruto de una drástica remodelación del patio que condenó las albercas y parterres primitivos y redujo el tamaño del espacio abierto hasta la proporción cuadrada. Tal transformación habría comportado el construir nuevos pórticos en ambos frentes para cuya cimentación fue preciso disponer una estructura muraria corrida que es la que hoy vemos que limita los parterres y albercas más antiguos y que obligó a enterrar albercas y jardines para disponer los corredores de los nuevos pórticos. Esta transformación también habría acarreado el macizado de los pórticos almohades para convertirlos en muros de cierre del nuevo pórtico, confirmando la hipótesis apuntada por Rafael Manzano para explicar que sus restos aparecieran en la escombrera sin haber sido localizados in situ ${ }^{13}$.

Hoy sabemos, por la constatación que nos proporcionan bastantes casos similares, que en los palacios andalusíes transformados tras su paso a manos cristianas, fue un proceso muy corriente reducir los patios avanzando nuevos pórticos, ya sea en uno o en ambos frentes. La simpleza y en cierto modo también, pobreza espacial de las estructuras cubiertas de las casas y palacios andalusíes no eran fácilmente adaptables a las necesidades de los nuevos pobladores cristianos. La estructura basada en una simple sala, de no mucha anchura y precedida por un

13 Manzano 1995a:349.

Al-Qanțara (AQ) XXVIII 1, enero-junio 2007, pp. 181-228 ISSN 0211-3589 
pórtico, resultaba de reducida utilidad, sobre todo cuando se pasaba de un uso restringido y doméstico, en el concepto musulmán del término, a otro más público que requería poder dar cabida a un grupo más numeroso de personas. La casa de un musulmán, introvertida y restringida al solo acceso de los miembros de la familia o sus allegados, que al fin y al cabo eso seguía siendo cualquier palacio, difícilmente podía resolver las necesidades de una residencia cristiana, ya fuera regia o de un noble o persona acomodada ${ }^{14}$. Surge entonces la necesidad de agrandar las salas de la casa o palacio, y el procedimiento más simple es cerrar el primitivo pórtico convirtiéndolo en una nueva sala paralela a la anterior y construir un pórtico nuevo robando espacio al patio. Actuaciones de este tipo las podemos contemplar en el mismo Patio de Crucero del alcázar sevillano, en su lado meridional, con la reforma realizada por Alfonso X ${ }^{15}$, en el lado norte del Palacio de la Aljafería, tras la reforma llevada a cabo por Pedro IV ${ }^{16}$, o la conversión de la $D \bar{a} r$ al-Șugrà o Alcázar menor de Murcia en convento de clarisas ${ }^{17}$. En todos los casos se duplican las salas cerradas y se construye un nuevo pórtico en el espacio del patio. Este proceso ha podido también tener su precedente o referencia en algunos ejemplos de dobles salas que existen en Madinat al-Zahrā', en concreto en la Dār al-Mulk y en el lado occidental del Patio de los Pilares ${ }^{18}$. Es interesante constatar cómo el modelo se aplicó incluso en construcciones de nueva planta como es el caso de la Cámara Real del Palacio del rey D. Pedro del Alcázar de Sevilla, situado en el lado norte del Patio de las Doncellas ${ }^{19}$.

Creemos que, a la vista de los indicios con que contamos, un proceso similar se ha producido en el patio que estamos analizando, con la particularidad de que en este caso, el proceso aun continuó, como tendremos ocasión de explicar, al reducirse en una etapa posterior las dimensiones del espacio libre para lograr mayor superficie construida. En varios de los casos antes mencionados, el proceso de expansión hacia el patio estuvo acompañado de la creación de una segunda planta, que en nuestro caso sólo podemos aseverar en la última fase de su transformación.

14 Cómez 1996:76

5 Almagro 1999:344-351.

16 Martín-Bueno, Sáenz 1998:160.

7 Navarro 1995:178; 2004:122; Pozo 1999:101.

18 Almagro 2001:fig. 7 y 10; 2004:119, 124.

19 Almagro 2000:pl. 26.

Al-Qanțara (AQ) XXVIII 1, enero-junio 2007, pp. 181-228 ISSN 0211-3589 


\section{Cronología de la reforma cristiana}

Admitida la hipótesis de que lo que hoy vemos corresponde únicamente a dos períodos básicos, uno almohade y otro posterior, surge inmediatamente la pregunta de a qué momento pertenece la modificación que hemos descrito con la reducción del patio a una planta cuadrada y la organización de jardín en crucero con alberca central prolongada en sus cuatro brazos. Las nuevas investigaciones y hallazgos arqueológicos recientes nos aportan luz para afrontar esta cuestión.

Seguramente los elementos más significativos de este período sean los que conforman el perímetro de los parterres rehundidos del jardín. Están constituidos por muros de ladrillo decorados con arcos ciegos en relieve, de forma apuntada, sin impostas marcadas ni forma de herradura ${ }^{20}$. Cabalgando sobre cada dos arcos, a la altura de las albanegas, se disponen unos arquillos que dejan un espacio con forma de lágrima, que recuerdan elementos de aligeramiento estructural como los que presentan el acueducto de los «Caños de Carmona» en Sevilla ${ }^{21}$ o los arcos centrales del aljibe del Castillo de Jimena de la Frontera (Cádiz) ${ }^{22}$. En los ángulos achaflanados aparecen otros arcos, estos ya de herradura. Todos ellos tienen sus fondos pintados representando puertas de madera con tablas, clavos y herrajes. Aunque estas sencillas formas enlazan fácilmente con la sobriedad del arte almohade, tuvieron una larga pervivencia en todo el arte posterior y de manera especial en las manifestaciones mudéjares.

La aparición de la estructura del jardín del patio del Palacio de Pedro I en el Alcázar de Sevilla (Patio de las Doncellas) ${ }^{23}$ con una disposición de parterres rehundidos rodeados por muros con arquerías ciegas, en este caso de arcos entrecruzados, permite también poner en duda la adscripción almohade de las estructuras más recientes del jardín del patio de la Casa de Contratación y suponer una más que probable datación cristiana, seguramente del siglo XIV. Como ya hemos dicho, las formas simples de las arquerías ciegas son de cronología muy difusa y nada impide considerarlas de este período. Por otro lado debemos pensar que los modelos almohades estaban a la vista de los

20 Dibujo de L. Ramón-Laca en Jiménez 1995:247.

21 Jiménez 1995:144, 237.

22 Jiménez 1995:146.

${ }^{23}$ Almagro 2005a; Tabales 2003a; 2005.

Al-Qanțara (AQ) XXVIII 1, enero-junio 2007, pp. 181-228 ISSN 0211-3589 
nuevos dominadores y que tenían por tanto esquemas y formas para copiar. Lo mismo cabe decir de las pinturas que decoran los muros laterales de las albercas. Las de diseño geométrico que imitan ondas resultan totalmente atemporales. En cuanto a las de la alberca circular central (Fig. 13), creemos que sus motivos florales encajan mejor con una cronología más avanzada que la hasta ahora mantenida de finales del XII o principios del XIII. En especial las florecitas de cuatro pétalos que acompañan a las hojas de palma y la forma en que éstas se agrupan saliendo de un haz vertical, tienen un carácter más naturalista que el que caracteriza el abstracto arte almohade.

En el siglo XIII y después de la conquista de Sevilla en 1248, sólo tenemos constancia de la realización de obras de cierta envergadura con la intervención realizada en el Patio del Crucero. Ésta tiene un carácter muy distinto de la obra que aquí analizamos. En el patio del Crucero se construye un nuevo edificio en el estilo propio de los nuevos conquistadores. Es cierto que se conserva el espíritu del primer edificio concebido como un patio con salones contrapuestos de acuerdo con el modelo de casa andalusí, pero los salones de nueva construcción se realizan en lenguaje gótico. Tenemos que avanzar hasta pleno siglo XIV para encontrar de nuevo un resurgimiento del lenguaje tradicional de al-Andalus, tanto en los dominios cristianos como en los musulmanes ${ }^{24}$. Con Pedro I podemos constatar la existencia de un magno programa de renovación del Alcázar, quizás iniciado en tiempos de su padre Alfonso XI, pero que en sus líneas fundamentales hay que atribuir al hijo. A este programa, del que ahora empezamos a vislumbrar su verdadera magnitud, creemos puede atribuirse la renovación del patio que estamos analizando y que tuvo por objeto ampliar sus áreas habitables. Como tendremos ocasión de exponer más adelante, el proyecto de Pedro I iba mucho más allá de la simple construcción de un nuevo palacio dentro del Alcázar y es muy probable que la renovación de esta antigua construcción de época almohade formara parte del mismo. La prematura muerte de este monarca debió dejar inconclusas partes primordiales de su plan. Desgraciadamente la escasez de datos documentales no nos permiten ir mucho más adelante en nuestras conjeturas.

${ }^{24}$ Ruiz Souza 2004:24.

Al-Qanțara (AQ) XXVIII 1, enero-junio 2007, pp. 181-228 ISSN 0211-3589 


\section{Una nueva hipótesis}

\section{El patio almohade}

Recapitulando lo hasta ahora dicho podemos plantear una nueva interpretación para este conjunto ubicado en lo que después vino a ser la Casa de Contratación. Nada sabemos, hasta ahora, de las estructuras que pudo haber de época anterior a lo almohade. Ninguna excavación con la suficiente profundidad se ha realizado en esta zona. Las que pudieran tener más directa relación, realizadas en el Patio de la Montería y en el Jardín del Príncipe, constatan la presencia de estructuras atribuibles al período abbadí en cotas muy inferiores a las del actual patio.

En época almohade existió un edificio de gran tamaño y carácter residencial que hemos de considerar como un palacio (Fig. 3). Poseía un patio rectangular de $30.20 \times 22,50 \mathrm{~m}$ orientado en dirección noroeste-sureste, que a efectos descriptivos consideraremos como simplemente norte-sur. Las dimensiones totales del edificio podemos suponerlas de unos 49,00 $\mathrm{m} \times 31,50 \mathrm{~m}$. En los dos lados más cortos dispuso de salas alargadas precedidas de pórticos. Sólo en el lado norte se ha conservado el muro de separación entre ambos, con un hueco tripartito de formas arcaizantes. El pórtico se habría conservado después de su macizado y conversión en muro de crujía hasta la demolición del edificio realizada en los años 60 de la pasada centuria. Dicho pórtico ha podido ser reconstruido con elementos originales recogidos de los escombros del derribo, y suponemos que en base a restos de la cimentación (Figs. 4 y 5). En el lado sur, el muro de separación entre sala y pórtico y el pórtico mismo debieron desaparecer con las trasformaciones realizadas para habilitar el edificio como Casa de Contratación como luego analizaremos. Las salas tenían una anchura de unos 4,25 $\mathrm{m}$ y los pórticos de 3,20 $\mathrm{m}$.

En los lados mayores del patio debieron existir crujías de menor anchura. De la oriental no ha quedado ningún testimonio, pero de la occidental existe una referencia suficientemente fiable que es la presencia de una crujía estrecha que aparece dibujada en el plano del Alcázar realizado por Joaquín Fernández en $1872{ }^{25}$ (Fig. 19). Por la

${ }^{25}$ Fernández, J. 1872, Plano General de los Reales Alcázares de Sevilla y sus pertenencias, declarado del patrimonio de la Corona, Archivo General del Palacio Real de Madrid, plano 1239.

Al-Qanțara (AQ) XXVIII 1, enero-junio 2007, pp. 181-228 ISSN 0211-3589 
documentación conservada sabemos que esta crujía estrecha era la única que existía hasta la ampliación de la Casa realizada en 159326 tomando suelo de la plaza inmediata. Esta crujía tenía una anchura de unos 3,50 m.

En la zona descubierta del patio su organización hemos de reconstruirla en base a los restos conservados y a la disposición encontrada en otros patios semejantes. Frente a los pórticos había sendas albercas que hemos de suponer rectangulares, pues su verdadera dimensión quedó truncada con la posterior transformación del conjunto. El paralelo más cercano cronológicamente al que nos ocupa y con dimensiones comparables es el del Castillejo de Monteagudo, construcción mardanisí erigida junto a la Vega de Murcia entre 1147 y $1165^{27}$. Este edificio poseía un patio rectangular con un jardín de crucero y dos albercas delante de cada pórtico. Creemos que una disposición similar sería la que contendría el patio que estamos analizando, aunque con algunas pequeñas diferencias (Figs. 8 y 9). También tiene una disposición semejante el patio principal del llamado Alcázar de los Reyes Cristianos de Córdoba, obra de la primera mitad del s. XIV, cuya construcción se atribuye a Alfonso XI ${ }^{28}$.

Resulta curioso que casi nadie haya prestado atención al hecho de que el pórtico norte se encuentra cerca de medio metro más alto que el del lado sur, seguramente por condicionantes topográficos. Dado la gran profundidad a la que se halla el terreno de plantación de los jardines, es comprensible que se contara con andenes laterales a menor altura (Figs. 4 y 6), lo que permitiría además disponer una doble planta en las crujías laterales, estando sus habitaciones de la planta inferior a una cota más baja que los salones principales, como seguramente también ocurría en el Castillejo de Monteagudo. Para descender desde el nivel del pórtico norte a los andenes laterales se construyeron rampas simétricas de bajada que arrancan de la plataforma de la alberca y descienden hasta los ángulos del patio en que se alcanza la cota de los andenes laterales. Podemos suponer que entre la plataforma de la alberca y el andén central habría también una rampa o algunos peldaños. Los andenes a menor cota permitirían disfrutar del jardín con más facilidad. Al menos en uno de los arriates se han

26 Gil-Bermejo 1973:34.

27 Navarro, Jiménez 1995:73.

${ }^{28}$ Escribano 1972:74-80.

Al-Qanțara (AQ) XXVIII 1, enero-junio 2007, pp. 181-228 ISSN 0211-3589 
conservado otros andenes perimetrales a la cota del terreno. De este modo se podía gozar del jardín y de sus frutos desde prácticamente tres niveles distintos: uno a escasos $20 \mathrm{~cm}$ del suelo, otro a $1,20 \mathrm{~m}$ y otro a casi $2,00 \mathrm{~m}$ que ofrecerían distintas perspectivas y la posibilidad de alcanzar los frutos de las plantas de distinto porte. Los andenes laterales llegan al pórtico sur casi a la misma altura de su pavimento, existiendo sólo una ligera rampa de subida hasta el borde de la alberca de ese lado. De todos modos parece que los andenes no tuvieron sus pavimentos totalmente horizontales, pues en el lado oriental del lado sur no existe rampa, lo que permitiría suponer que el andén de ese lado estaba algo más alto que el del opuesto. De los andenes centrales del crucero, tanto del longitudinal como del transversal no ha quedado ningún resto, por lo que la planta propuesta no deja de ser una mera hipótesis basada en el paralelo antes mencionado.

El pórtico septentrional pudo ser reconstruido gracias a los restos recuperados tras el derribo. Su alzado presenta un gran arco central que arranca del típico motivo almohade de doble voluta conocido por algunos como serpentiforme (Figs. 4 y 5). Su intradós se ha reconstruido con lóbulos alternos, unos mayores circulares y otros menores de doble arco, sin que exista, al parecer, ningún elemento original, salvo el arranque mencionado. A ambos lados del arco central se dispusieron dos vanos dobles. Estos vanos están separados por pilares que delimitan grandes paños de sebka que arrancan de arcos geminados con perfil lobulado cuyas arcuaciones forman oyuelos en los vértices como si se trataran de hojas de palma que se empiezan a abrir. Los arcos geminados se apoyan en columnas centrales. El gran tamaño del patio y la elegancia de las formas adoptadas confiere a este alzado un carácter de gran monumentalidad, acentuado sin duda por el hecho de ser uno de los de mayores dimensiones de los conservados en la arquitectura andalusí.

El pórtico, en su interior, tuvo al parecer atajos en sus extremos formados por pórticos de doble arco dispuestos en sentido perpendicular. Posiblemente, estos atajos se correspondan con los que formarían las alhanías del salón inmediato. Parece que en los extremos del pórtico, dentro de los atajos, hubo puertas hacia las alhanías y hacia el exterior del patio, aunque esto no es plenamente comprobable por encontrarse tapiados, lo que también permite suponer que pudiera tratarse de simples arcos decorativos. Sólo en el extremo oriental existe uno abierto que actualmente comunica con un patio y que parece ser 
que sí fue puerta. Como ya hemos comentado, nada se ha conservado del pórtico sur, salvo lo que parece ser el apoyo de una de las columnas en una posición semejante a las del lado opuesto. Por ello podemos considerar que este pórtico tendría similar forma y disposición que el septentrional, manteniendo de este modo la simetría característica de estos edificios.

Este palacio debió formar parte de un gran programa constructivo desarrollado por los califas almohades en su capital andalusí, seguramente en relación con otros edificios ${ }^{29}$, algunos de los cuales fueron destruidos al acometerse el gran proyecto llevado a cabo por Pedro I y del que luego hablaremos.

\section{El patio cristiano}

En una fecha que desconocemos, pero que podemos imaginar hacia mitad del siglo XIV, se produjo una drástica transformación del edificio y de su patio. La necesidad de mayor espacio habitable motivó que los pórticos almohades se tapiaran y convirtieran en muros, seguramente con una puerta central y varias ventanas (Fig. 9). Se construirían nuevos pórticos más avanzados hacia el centro del patio, que le conferirían una planta casi cuadrada de 21,90 m. $\times 22,50 \mathrm{~m}$. El mantenimiento del ancho del patio, atestiguado por la situación de los andenes de ambos períodos nos permite asegurar que se continuó manteniendo el modelo de patio con salones y pórticos contrapuestos y no se adoptó el de patio con pórticos en todo su perímetro. De la existencia de estos pórticos nada ha llegado salvo la presencia de su cimentación y de sus improntas en el muro oriental. En el ángulo sureste existe hoy un machón, con apariencia de contrafuerte, en el que se puede apreciar que su cara oeste y sus aristas son fruto de intervención reciente. Coincide en su posición con la línea en que acaba el pavimento de los andenes de la zona central y se produce un descenso a los inmediatos al pórtico, que suponemos almohades. Esta línea de muro es también la que cercena la alberca. En el lado norte, sólo se conserva el arranque de un arco que pudo corresponder a una puerta abierta en el muro con el que quizás se tapió también la arquería de

29 Tabales 2000:37-39; 2001a.

Al-Qanțara (AQ) XXVIII 1, enero-junio 2007, pp. 181-228 ISSN 0211-3589 
ese frente en una fase posterior (Fig. 17). No obstante, trataremos más adelante de la problemática del edificio a partir del siglo XVI.

Las zonas cubiertas de estos pórticos se igualaron rellenando hasta el nivel de su suelo las albercas y los parterres que quedaron ocultos. En el lado oriental del pórtico norte se construyó un aljibe que aún perdura, aprovechando el hueco del parterre primitivo. En la zona descubierta del patio, la configuración del jardín y de sus andenes quedó drásticamente trasformada (Fig. 10). Se mantuvo la estructura de crucero, pero con amplios andenes atravesados por albercas rectangulares que se unen a otra central de forma circular, en medio de la cual se dispuso una fuente con pila (Fig. 11). Cuatro puentecillos delimitan a nivel del pavimento las cuatro albercas rectangulares y la alberca circular permitiendo que por debajo se comuniquen formando un vaso único. Como ya hemos dicho, el crucero conforma cuatro arriates o parterres de jardín, cuyo suelo se encuentra dos metros por debajo del suelo de los andenes. Los muros que cierran estas zonas de jardín presentan una decoración de arcos ciegos con pinturas representando puertas cerradas por hojas de madera con clavos y herrajes (Fig. 12).

El aspecto de este jardín resulta muy semejante al recientemente descubierto del Patio de las Doncellas, salvo que aquél no presenta disposición de crucero y éste tiene el jardín a casi el doble de profundidad. Sin embargo, ambos poseen a nuestro entender algo más en común: su gran originalidad y su carácter en cierto modo revolucionario e innovador, algo que entendemos caracteriza la arquitectura de este momento, tanto en las obras de Pedro I como en las de Muhammad V, su amigo y aliado. Aun cuando ambos patios se insertan plenamente en la cultura arquitectónica andalusí, no es fácil encontrar precedentes directos, ni para la alberca inicialmente proyectada en el Patio de las Doncellas, ${ }^{30}$ ni para la de éste que analizamos. En el patio del Palacio de D. Pedro parece que se proyectó inicialmente una alberca con disposición longitudinal, pero con remates en forma de «T» en sus extremos. No sabemos si se pensó en construir puentecillos, como los del Patio de Contratación, para aparentar una alberca alargada y dos pequeñas transversales frente a los pórticos, aunque manteniendo un recipiente único de agua. No obstante, ningún resto ni indicio de tales puentes ha aparecido, por lo que en principio hay que pensar en una

30 Almagro 2005.

Al-Qanțara (AQ) XXVIII 1, enero-junio 2007, pp. 181-228 ISSN 0211-3589 
alberca con forma de doble «T». Cualquiera que fuera la forma pensada para esta alberca, no cabe duda de que resulta de gran originalidad, como también lo fue la construida por Muhammad V en el patio del Mexuar de la Alhambra, inspirada sin duda en un modelo romano, pero totalmente anómala en la arquitectura andalusí ${ }^{31}$. Lo mismo cabe decir de la alberca o albercas del Patio de Contratación. Disposición tan compleja como la aquí adoptada no se conoce ni en casos precedentes ni en ninguna obra nazarí contemporánea o posterior.

Con esta hipótesis planteamos un patio (Figs. 14 y 15) radicalmente distinto del que ahora vemos que, basado en una interpretación que creemos errónea, viene a mostrar la presencia simultánea de estructuras diacrónicas que pueden interpretarse como un documento de lectura compleja, pero nunca como una situación real existente en un período anterior. Nuestra hipótesis vendría además confirmada por la explicación de las trasformaciones posteriores que sufrió el edificio y que vamos a tratar de analizar a continuación. Pero sí queremos en este momento aludir a un dato que nos parece bastante relevante y que tiene relación con el nombre que al parecer se daba al edificio a comienzos de siglo XVI y que según nuestra interpretación pudo ser el de «Cuarto de los cuatro palacios». Sabido es que el término «palacio» se aplicaba para mencionar la sala principal de una casa o una sala de planta baja ${ }^{32}$. Creemos que este nombre encaja perfectamente con la disposición que hemos supuesto del edificio tras la reforma cristiana en la que los pórticos primitivos se convirtieron en salas, duplicando de este modo las originales con lo que el conjunto vino a contar con dos salas o «palacios» en cada extremo del patio, y por tanto cuatro en total, lo que justificaría el nombre antes aludido.

\section{El patio renacentista}

En 1503, los Reyes Católicos ordenaban la construcción de la Casa de Contratación para alojar la institución que durante casi tres siglos había de dirigir y monopolizar el comercio con el recientemente descubierto Nuevo Mundo. Para tal fin se destinaron inicialmente el llamado «Cuarto de los almirantes» y el «Cuarto de los cuatro pala-

31 Orihuela, López 1990:126.

32 Diccionario de la Real Academia Española, voz "palacio", 40 acepción. 
cios» ${ }^{33}$. En la Real Cédula que contiene las instrucciones para su edificación se hace hincapié en que se haga con poco costo, para que se vaya mejorando con el tiempo. Esto permite pensar que de hecho no se construiría de nueva planta, sino que se habilitarían las edificaciones existentes. La localización precisa del «Cuarto de los almirantes» y del «Cuarto de los cuatro palacios» no resulta hoy por hoy posible hacerla con absoluta seguridad. Según la interpretación que hemos adelantado, creemos que este último puede identificarse con el antiguo palacio almohade, trasformado en época cristiana y que estamos estudiando. El «Cuarto de los almirantes» podría corresponder a la zona existente entre el anterior y el Patio del León, área que desde sus orígenes parece que quedó adscrita a la Casa de Contratación, aunque tras la desaparición de este organismo pasó de nuevo al Alcázar, a cuyas dependencias pertenece en la actualidad. La denominación que hoy se da a la llamada Sala del Almirante, en el lado occidental del patio de la Montería, nos parece equivocada, ya que esa zona se menciona siempre en los documentos como "Cuarto de la Montería» ${ }^{34}$.

Inicialmente parece que sólo una parte del edificio fue destinado a formar parte de la Casa por oposición del rey a que se ocupara otra parte de él, que finalmente autorizó a incorporar entre 1509 y 1515. De acuerdo con la primera descripción que poseemos del edificio ${ }^{35}$ ya adaptado a su nuevo uso, podemos decir que las salas del lado sur se destinaron a almacén, se abrió la puerta principal hacia el oeste, en la crujía lateral, que contaba con dos pisos que seguramente ya existían en el edificio almohade y en el lado norte se dispuso una capilla bajo la advocación de Santa Isabel a la que más tarde se añadiría una sala para las audiencias ${ }^{36}$. Pensamos que estas dos últimas dependencias ocuparían los dos salones paralelos del lado norte del antiguo palacio tras ser modificado en época cristiana. Los del lado sur y su correspondiente pórtico parece que fueron derribados para construir el almacén, según se desprende tanto de la documentación como de la planta del edificio realizada en 1872 y que nos permite intuir que ocu-

33 Gil-Bermejo 1973:680.

34 Gil-Bermejo 1973:Fig. 5; Almagro 2005. ${ }^{\mathrm{a}}$

35 Gil-Bermejo 1973:681-682. Las dimensiones que se dan en esta descripción cuadran con cierta aproximación con las que podemos deducir del plano por nosotros dibujado. Sólo discrepan de forma llamativa las relativas al patio, que creemos deben estar dadas en varas y no en pies.

36 Gil-Bermejo 1973:696.

Al-Qanțara (AQ) XXVIII 1, enero-junio 2007, pp. 181-228 ISSN 0211-3589 
pando el espacio de la tres crujías primitivas se dispusieron dos más anchas y comunicadas por una panda de arcos sobre pilares. Este almacén se vino poco después a llamar la Sala del Tesoro, pues en él se almacenaban los metales preciosos que llegaban de América. La certeza de esta trasformación vendría además avalada por el hecho de que Rafael Manzano no encontró en este lugar restos de la obra almohade, salvo quizás los cimientos, a diferencia de lo ocurrido en el lado norte en donde parece que sí se mantuvieron las crujías iniciales. Parece, por las descripciones mencionadas, que una de las primeras transformaciones que se realizaron en el patio fue dotarle de un pórtico adosado a la crujía occidental, con su correspondiente galería superior ${ }^{37}$. El pórtico resultaría imprescindible para comunicar, bajo cubierto, las dependencias de los lados sur y norte. La galería lo sería para permitir un acceso adecuado a las dependencias del piso superior de la crujía occidental, cuya escasa anchura no permitía disponer de un pasillo de circulación dentro de ella. Contigua a la puerta por su lado sur y con acceso desde el pórtico se dispuso la escalera, cuya forma y trazado no debió variar con el tiempo y podemos imaginar tal y como aparece en el plano de 1872.

Pensamos que desde el inicio de estas trasformaciones, realizadas en el primer tercio del siglo XVI, se procedió a enterrar los jardines y albercas del patio, al constituir un estorbo para el nuevo funcionamiento del edificio e interferir especialmente con el pórtico construido en el lado oeste. En fecha ya avanzada, entre 1556 y 1561 se procedió a dotar al patio de pórticos y galerías altas en sus cuatro lados, con arcos sostenidos por 16 columnas ${ }^{38}$. Esta transformación definitiva del patio pudo deberse, aparte del deseo de dotarlo de un nuevo y mejorado aspecto, a haberse dividido en altura los salones de los lados norte y sur y precisar por ello de un acceso adecuado (Fig. 16).

El número de 16 columnas que nos proporciona la documentación de la época, nos sugiere un patio de planta cuadrada con cinco columnas en cada frente, incluyendo las de los ángulos. Esta hipótesis encaja perfectamente con un plano conservado en el despacho de la Dirección del Alcázar, fechado en 1834 (Fig. 18), en que aparece el patio dibujado con forma cuadrada y dieciséis columnas. Según esta hipótesis, los nuevos pórticos se habrían construido tras cegar los precedentes de la

37 Gil-Bermejo 1973:681.

38 Gil-Bermejo 1973:703.

Al-Qanțara (AQ) XXVIII 1, enero-junio 2007, pp. 181-228 ISSN 0211-3589 
reforma que suponemos del siglo XIV y adelantándolos en los cuatro lados hacia el interior del patio, siguiendo el proceso de reducción del espacio abierto ya iniciado en la reforma anterior. Esta teoría cuadra perfectamente con los restos conservados en el muro oriental del patio en donde aún se ve in situ la imposta decorativa del arranque de un arco que sería el de prolongación de la arquería del lado norte para transmitir sus empujes hasta el muro (Fig. 16, n. ${ }^{\circ} 1$ y Fig. 17). Esta imposta, con forma de capitel de pilastra realizada en yeso y de gusto clasicista, cuadra perfectamente con la fecha de construcción de los pórticos. Sobre ella se conserva aún el arranque del arco realizado con un pie y medio de ladrillo y enlucido. Un poco más al norte, y coincidiendo con la línea en donde suponemos se construyó el pórtico del siglo XIV, se conserva el arranque de otro arco (Fig. 16, n. ${ }^{\circ}$ 2), de dos pies de ancho, que por la altura a la que se inicia podemos suponer de una puerta o paso abierto en el muro en que finalmente se convirtió dicho pórtico. En el extremo sur no se ha conservado la imposta pero sí el arranque del arco de prolongación del pórtico (Fig. 16, n. ${ }^{\circ} 3$ ), también de un pie y medio de ladrillo. Algo más al sur se conserva el machón (Fig. 16, n. ${ }^{\circ}$ 4), anteriormente descrito, que correspondería al muro que sustituyó o macizó el pórtico anterior correspondiente de este lado. De acuerdo con estos vestigios, y según hemos representado en nuestro plano, resulta un patio cuadrado de unos $15,10 \mathrm{~m}$. de lado en su parte descubierta y unos 22,50 m. entre muros.

Esta hipótesis encuentra sin embargo una contradicción en el plano de 1872 (Fig. 19), en donde el patio aparece dibujado con cinco columnas en los lados norte y sur, y con seis en los correspondientes al este y oeste. El muro norte de cierre del patio no corresponde por tanto con la línea del supuesto pórtico del siglo XIV sino con la del pórtico almohade. Esta representación, que por otro lado parece muy verosímil dada la buena calidad general del plano y su minuciosidad, no responde sin embargo a la realidad de los restos conservados y que venimos de describir, ni a los datos documentales ya aludidos. Podría pensarse que la imposta correspondiera a un arco que en su otro extremo no apoyara en la columna de ángulo sino en la primera de la panda occidental. Sin embargo, eso sólo tendría sentido si la cubrición de los pórticos se hubiera realizado con bóvedas baídas, lo que no parece aceptable pues no hay ningún resto de sus arranques y tampoco resulta una solución normal para esta época. Por otro lado, esta hipótesis tampoco cuadra con los restos del extremo sur, en donde lo represen- 
tado en el plano que mencionamos coincide plenamente con nuestra teoría. La única explicación que se nos ocurre, pero para la que no tenemos ninguna confirmación, sería que entre 1834 y 1872 se hubiera producido una reforma del patio que hubiera procedido a agrandarlo de nuevo hacia el norte.

A partir de 1592, y tras un intento infructuoso iniciado en la precedente década para agrandar la Sala del Tesoro a costa del «Corral de las piedras» perteneciente al Alcázar ${ }^{39}$, se realiza una ampliación de la Casa construyendo una nueva crujía adosada a la occidental, tomando terreno de la plaza. Con esta obra hubo que trasladar la portada de piedra hasta la alineación de la nueva fachada, dotando al edificio de un nuevo vestíbulo. En el plano de 1872 se aprecian con toda claridad las dos crujías resultantes, la primitiva, estrecha por corresponder a la crujía lateral del edificio almohade, y la nueva de mayor anchura.

Tras el traslado de la Casa de Contratación a Cádiz en 1717, el edificio se destinó a diversos usos en su mayoría relacionados con el Alcázar inmediato, al que quedó de nuevo adscrito tras la extinción de la institución en 1793. A partir de entonces el inmueble se dedicó a viviendas y alojamiento del séquito real cuando visitaba Sevilla. No sabemos en qué momento se segregó la primitiva sala septentrional del palacio almohade para integrarla en la casa $n^{\circ}{ }^{\circ} 3$ de la actual calle Miguel de Mañara. Parte de la antigua Sala del Tesoro estaba convertida en patio de luces en los últimos tiempos de existencia del inmueble. Todo esto denota la situación de abandono y desentendimiento por parte de los responsables del antiguo Patrimonio Real hacia este edificio de altísimo interés histórico y que además conservaba en sus entrañas elementos de indudable valor artístico, que finalmente abocará a su lamentable demolición en la década de los años sesenta del pasado siglo.

\section{El Alcázar de Pedro I 40}

La teoría que acabamos de exponer obliga a encuadrar la fase constructiva medieval cristiana en su propio contexto. Hemos aventu-

39 Gil-Bermejo 1973:708-710.

40 Para una apropiada visualización de las hipótesis que aquí apuntamos recomendamos visionar el audiovisual en DVD "El Alcázar de Sevilla en el Siglo XIV" (Almagro 2006).

Al-Qanțara (AQ) XXVIII 1, enero-junio 2007, pp. 181-228 ISSN 0211-3589 
rado una cronología de mediados del siglo XIV, a la vista de los recientes hallazgos que obligan a poner esta fase de organización del patio en línea con otras construcciones del Alcázar sevillano. La aparición de las estructuras del jardín del Palacio de D. Pedro en el Patio de las Doncellas permite, como ya hemos dicho, relacionarlas con las del patio de la Casa de Contratación, pero también obligan a revisar otros restos o estructuras, tales como los arcos que acompañan a la llamada Puerta de la Montería, que comunica el patio del mismo nombre con el Patio del León (Fig. 20). Esos arcos de ladrillo, que se complementan con unos sencillos arcos ciegos ornamentales dispuestos en sus albanegas, se han considerado hasta ahora como almohades ${ }^{41}$, pese a que claramente constituyen una estructura adosada a la muralla de tapial y acompañan a una puerta central construida con jambas de cantería ornadas con los escudos de Castilla y León semejantes a los que aparecen en la portada del Palacio de D. Pedro ${ }^{42}$.

La revisión de todo este conjunto a través de un análisis de la planimetría, pone también de manifiesto otras estructuras que podemos examinar con nuevas perspectivas, pues parecen tener una clara relación con el objeto de nuestro estudio. Nos referimos en concreto a las construcciones situadas en el lado occidental del Patio de la Montería, y que están en parte adosadas al palacio almohade de la Casa de la Contratación (Fig. 21). Entre ellas está la que hoy recibe el nombre de Sala del Almirante, a nuestro entender impropiamente pues esta zona se conocía, de acuerdo con la documentación, como Cuarto de la Montería. Así se cita en distintos documentos del siglo XVI ${ }^{43}$ y en particular en un plano y su documento anejo publicado por Juana Gil-Bermejos ${ }^{44}$ sobre una propuesta para ampliar la Sala del Tesoro de la Casa de Contratación, donde se rotula esta zona como Cuarto de la Montería.

Si estudiamos la planimetría histórica existente del Alcázar, en concreto el plano atribuido a Vermondo Resta de hacia 1608 (Fig. 22), el de Sebastián van der Borcht de 1759 (Fig. 23) o el de Joaquín Fernández de 1872 (Fig. 19), podemos observar que, aunque con una distribución de habitaciones cambiante, esta zona ha mantenido una estructura inalterada basada en un pórtico hacia el patio, una cru-

41 Valor 1991:115; Tabales 2002:39.

42 Cómez 1996:21.

43 Marín 1990:242-250.

Al-Qanțara (AQ) XXVIII 1, enero-junio 2007, pp. 181-228 ISSN 0211-3589 
jía alargada y una sala cuadrada adosada a la anterior aproximadamente en su centro. Ambas encajan perfectamente con el edificio de la Casa de Contratación dando la impresión de haberse construido en clara relación con ella. Si prescindimos de los muros y tabiques que subdividieron, según las épocas, la crujía alargada, eliminamos los forjados y techos actuales de clara datación renacentista y hacemos desaparecer incluso la escalera construida en su extremo sur entre 1591 y $1593{ }^{45}$, nos aparece una estructura compuesta por un pórtico, hoy de estilo renacentista, una gran sala alargada del tipo característico en las residencias andalusíes y una gran qubba, de dimensiones idénticas a las del Salón de Embajadores del Palacio de D. Pedro (Fig. 24, n. ${ }^{\circ}$ 9). La pregunta que surge de inmediato es ¿para qué y cuándo se ha diseñado esta estructura que en años posteriores quedó subdividida y alterada y que hoy, al menos en planta, podemos de nuevo contemplar unificada?

La respuesta podemos encontrarla en un texto de Francisco María Tubino ${ }^{46}$ citando documentos del Archivo de Simancas, que aún no hemos localizado, que refiriéndose en 1530 al Cuarto de la Montería dice que «está principiado desde el tiempo del Rey D. Pedro», significando que permanecía aún inacabado en ese momento. Es decir, que esta estructura la inició Pedro I dejándola inconclusa, seguramente con los muros arrancados y a medio levantar, sin techos ni cubiertas y sin pórtico; todo lo que finalmente se añade a finales del siglo XVI ${ }^{47}$. Ubicadas en esta época y con un promotor bien conocido, las estructuras cobran un nuevo valor y significado, porque lo que aquí estaba proyectado no es sino la estructura de un gran salón de trono, a semejanza del Palacio de Comares de la Alhambra, compuesto por un patio, un pórtico, una gran sala oblonga dispuesta en sentido transversal y una qubba. La misma secuencia que nos proporciona el Patio de los Arrayanes, con el pórtico norte de dicho patio, la Sala de la Barca y Salón de Comares. A diferencia de la Alhambra, en el Alcázar de Sevilla la sala transversal es notablemente mayor $(38,50 \times 7,15 \mathrm{~m}$ frente a $24,00 \mathrm{~m} \times 4,32 \mathrm{~m}$ ) y la qubba ligeramente más reducida $(9,60 \mathrm{~m}$ de lado frente a $11,30 \mathrm{~m})$.

\footnotetext{
44 Gil-Bermejo 1973:709, fig 5.

45 Marín 1990:247-250.

46 Tubino 1886:90.

47 Marín 1990:242-250.
} 
¿Qué significado tienen todos estos elementos si los relacionamos entre sí? A nuestro entender nos muestran un proyecto global y ambicioso de intervención en el Alcázar, acometido por Pedro I, de una gran envergadura y con una clara proyección ideológica y política, que se vio frustrado por la prematura muerte del monarca (Fig. 24). Este proyecto se desarrolló a lo largo de un eje visual establecido fuera del recinto más antiguo del Alcázar en cuyo interior se levantaban las principales residencias que hasta entonces habían dado alojamiento a los monarcas musulmanes y cristianos. En 1358, el propio monarca ocupaba el «Palacio del Yeso» ${ }^{48}$ (Fig. 24, n. ${ }^{\circ}$ 4), seguramente como lugar de su residencia antes de iniciar este proyecto o durante su construcción. En ese momento se cita también el «Palacio del Caracol» (Fig. 24, n. ${ }^{\circ}$ 7). Ambos constituyen parte del alcázar más antiguo, primitivas residencias almohades transformadas por los monarcas castellanos. El gran proyecto de D. Pedro se realiza justo en paralelo respecto a estos dos palacios, pero fuera del primer recinto del Alcázar.

El proyecto promovido por Pedro I se basa en un eje visual, como ya hemos dicho, que arranca en la Puerta del León (Fig. 24, n. ${ }^{\circ} 1$ ), nuevo acceso del que se dota al Alcázar, justo frente a la Catedral, y que tiene como foco final la portada de su nuevo palacio privado. Este eje ha tenido que ser cuidadosamente proyectado desde un primer momento, pues tanto esta puerta como la de la Montería (Fig. 24, n. ${ }^{\circ} 2$ ), de la que ahora hablaremos, y la del palacio están perfectamente alineadas, produciéndose asimetrías en las composiciones que las acompañan por los lados que sólo se justifican en función de la cuidadosa ubicación de estos tres elementos. El objetivo de todo ello no puede ser más claro. La puerta del nuevo palacio y su suntuoso encuadre deben ser visibles desde el exterior del Alcázar, a través de unos filtros o diafragmas visuales que permitan entender que el acceso hasta la morada del monarca es algo controlado y por ende supone un privilegio para quien allí es aceptado. Pero a su vez, y a diferencia de lo que ocurre en otros palacios andalusíes, la morada del rey es visible y se hace ostentación de su grandiosidad e importancia. En suma, el palacio se convierte en un medio propagandístico que intenta situar la residencia del monarca por encima de cualquier otra, sirviendo así claramente al programa político emprendido por Pedro I, y cuyo obje-

\footnotetext{
48 López de Ayala, Crónica: 482.
} 
tivo no era otro que el fortalecimiento de la monarquía y el establecimiento de su supremacía por encima de la nobleza.

A medio camino entre la Puerta del León y la del palacio se encuentra la llamada Puerta de la Montería (Fig. 24, n. ${ }^{\circ}$ 2). Esta puerta atraviesa una antigua muralla islámica de tapia a la que se le ha adosado por su parte externa una estructura cuya parte central es de cantería y que se acompaña en los laterales por otras de ladrillo (Fig. 20). Nuestra opinión es que todo este adosamiento es coetáneo y que la falta de simetría que presentan las zonas laterales de ladrillo sólo se deben a la decisión de que la puerta central ocupe la posición exacta que tiene y que permite la visión a la que antes hemos aludido ${ }^{49}$. Así, esta puerta-fachada se compone de un arco central de medio punto con decoración de escudos de León y Castilla muy semejantes, como ya hemos dicho, a los de la Puerta del León y la portada del palacio, que se acompaña a ambos lados por dos paramentos de cantería que quedan interrumpidos a una cierta altura por lo que parecen ser los arranques de dos arcos perpendiculares a la fachada y que interpretamos, y así lo hemos representado, como integrantes de una construcción a modo de arco de triunfo a cimborrio levantado en la misma puerta del palacio ${ }^{50}$. No debemos olvidar que se trata de una puerta interior y por tanto protegida por un recinto más externo. Pensamos que esta estructura, si se confirma algún día su realidad, podría relacionarse con la noticia que recogen Rodrigo Caro y Espinosa de los Monteros de la existencia de un tribunal arrimado a la muralla junto a la puerta del Alcázar y cubierto por un cimborrio de cantería, en donde el rey administraba justicia ${ }^{51}$.

\footnotetext{
49 Durante el año 2005 se han realizado excavaciones en el Patio del León frente a esta muralla, que si bien no permiten corroborar totalmente nuestra hipótesis, tampoco la desmienten. La investigación realizada sí parece que permite suponer la coetaneidad de todo el frente adosado a la muralla islámica de tapia por tener un cimiento común. La aparición de numerosos vestigios escultóricos avalan también la prestancia que debió tener esta puerta, aunque la construcción de un corral de comedias dentro del Patio del León en el siglo XVII alteró notablemente el subsuelo en la zona cercana a la puerta impidiéndonos conocer si pudo existir una estructura saliente a modo de pabellón como en principio hemos supuesto. La construcción del foso bajo el escenario desfondó hasta una cota muy profunda toda esta área (Tabales 2006:24-28).

50 Esta idea ya ha sido propuesta por A. Jiménez (1998:52).

51 Cómez 1996:33 citando a Espinosa de los Monteros, Historia, antigüedades y grandeza de la muy noble y muy leal ciudad de Sevilla, Sevilla, 1627, f.22v; R. Caro, Antigüedades y principado de la ilustrísima ciudad de Sevilla, Sevilla, 1634, f.56).
}

Al-Qanțara (AQ) XXVIII 1, enero-junio 2007, pp. 181-228 ISSN 0211-3589 
Las estructuras laterales de ladrillo se componen cada una de un gran arco, cuyas albanegas se rellenan con arquillos ciegos, sencillos y de herradura apuntada en el lado derecho, y entrelazados en el izquierdo. En la jamba izquierda de ese lado se desarrolla este entrelazado hasta alcanzar tres arcos, gracias a la mayor extensión de dicho lado que también tiene el gran arco de ladrillo con mayor anchura que el del otro lado. Volvemos a insistir en que estas asimetrías se deben a la especialmente buscada posición de la puerta central. M. Valor y M. A. Tabales han interpretado que estos arcos laterales eran puertas de paso hacia zonas laterales del palacio, y R. Cómez ha expuesto sus dudas de que estos arcos en su origen estuvieran abiertos ${ }^{52}$. La planimetría histórica no apoya en absoluto la teoría de que fueran puertas y el análisis de su fábrica también parece contradecirlo. Toda la fábrica de ladrillo y en especial la que se ve por encima de los arcos está construida adosada a la fábrica más antigua del tapial de la muralla islámica. Por tanto, de haber existido puertas laterales atravesando la muralla, éstas tendrían que haber sido notablemente menores que los grandes vacíos que hoy observamos en ella y habrían sido por supuesto de mucha menor altura que los siempre mencionados arcos de ladrillo. En nuestra opinión, estos arcos eran ciegos y formaban parte de la ornamentación de esta primera fachada del palacio, procurando lugar de acomodo y protección para la guardia o para visitantes que aguardaban su entrada al mismo, como ocurre en tantos palacios de tradición oriental. El que esta fachada tenga su parte central de cantería y las laterales de ladrillo no hace más que repetir lo que ocurre en la fachada del palacio que encontramos a continuación, al fondo del Patio de la Montería.

A través de esta puerta se accede al Patio de la Montería (Fig. 24, n. $\left.{ }^{\circ} 3\right)$. Su planta actual es básicamente la misma que debió disponerse en la traza de mediados del siglo XIV, variando los alzados que en su mayor parte debieron quedar inacabados. El patio vino a ocupar el solar dejado por la demolición de una serie de edificios de época almohade que cabe suponer que se eliminarían para dar paso al nuevo proyecto palatino ${ }^{53}$. Este patio debió concebirse con pórticos en todo su perímetro, pues sólo eso explica las arquerías que acompañan a la portada del palacio. En el lado oriental, el pórtico estaría previsto arrimado a la muralla del recinto primitivo del alcázar, entre dos de sus

\footnotetext{
52 Cómez 1996:22.

53 Tabales 2000:37-39; 2001a.
} 
torres, cuyo derribo quizás se ejecutó o al menos planeó entonces, y albergando la puerta que daba acceso a los palacios del Yeso y del Crucero y Caracol, puerta que se cita como «Puerta Real que da al Crucero» en el siglo XVI ${ }^{54}$. En el lado norte el corredor o pórtico se tendría que adosar a la muralla de tapia ya mencionada, y en el lado occidental, el correspondiente pórtico se antepondría a la sala y qubba que hemos analizado anteriormente. El estudio de los planos históricos y una mención documental de $1589{ }^{55}$ nos permiten suponer que en el ángulo noroeste del patio existió un acceso al palacio que luego ocupó la Casa de Contratación y que ha sido el objeto principal de nuestro estudio (Fig. 24, n. ${ }^{\circ}$ 10). Según el documento de esta última fecha, en el zaguán que se construye en esa época a continuación de la Puerta de la Montería, en el lado norte del patio, existía una puerta de comunicación con dicha Casa. Este hecho creemos que pone en relación el palacio medieval cristiano estudiado con el proyecto general de ordenación del nuevo palacio del rey. La sala y qubba del lado occidental del Patio de la Montería (Fig. 24, n. ${ }^{\circ}$ 9), que se mencionan como Cuarto de la Montería, se proyectan y construyen en consonancia y alineación con el primitivo palacio almohade, lo que permite suponer que la reforma de este último pudo también formar parte del proyecto palatino de Pedro I.

Creemos que este conjunto tiene una interpretación propia. Todo él está concebido con un gran sentido simbólico y escenográfico. La Puerta del León es el enlace con el mundo exterior. A través de ella puede verse, en primer lugar, la primera puerta del palacio, la de la Montería, solio de la justicia del rey. Al fondo, a modo de gran dosel, se observa la portada del palacio, en cuya parte alta el rey tiene uno de sus salones de recepción, manifestado en forma de qubba elevada y desde cuyas ventanas puede presentarse ante los reunidos en el patio que se extiende a su frente. Entrando en éste, a mano derecha, se levanta un gran edificio, el Cuarto de la Montería, destinado a las recepciones públicas, compuesto por una sala, muy capaz, a modo de antesala, y un salón del trono con forma de qubba, máxima simbolización del poder soberano ${ }^{56}$. Si consideramos que la sala previa se levantaba con una sola planta, podemos imaginar que el

54 Marín 1990:243.

55 Marín 1990:246

56 Manzano 1994.

Al-Qantara (AQ) XXVIII 1, enero-junio 2007, pp. 181-228 ISSN 0211-3589 
volumen de la qubba resultaría perfectamente visible desde el patio. Por el extremo norte de esa sala y del pórtico que la precedía se accedía al «Cuarto de los Cuatro Palacios» después convertido en Casa de Contratación y que pudo haberse transformado para ser residencia de huéspedes ilustres. Enfrente del Cuarto de la Montería otro pórtico protegía la puerta de acceso a las antiguas residencias reales del Alcázar Viejo, el Cuarto del Yeso y el Patio del Crucero con el Cuarto del Caracol. Este último, comunicado internamente con el palacio nuevo, y dotado de amplios salones, podía servir para grandes reuniones de la corte. En el frente del Patio de la Montería se levantaba la nueva residencia privada del monarca (Fig. 24, n. ${ }^{\circ} 8$ ), concebida según el concepto de una vivienda doméstica andalusí, aunque con una mayor complejidad y un recurso especial a los elementos simbólicos. Además de la qubba del piso alto, visible sobre la fachada, el palacio contaba con otra gran sala-qubba centrando la composición del patio, el Salón de Embajadores, destinada sin duda a las recepciones privadas del monarca.

La combinación de sala transversal seguida de qubba, está presente ya desde mediados del siglo XII en el Castillejo de Monteagudo (Murcia) ${ }^{57}$, y tuvo un fuerte arraigo a partir de finales del siglo XIII tanto en el área de la España musulmana, ya reducida al reino nazarí, como en el reino de Castilla. Parece que estuvo presente en el palacio construido por D. Fadrique, hermano de Alfonso X, en la zona norte de la ciudad de Sevilla y luego convertido en Convento de Santa Clara ${ }^{58}$. También parece que se halla en el Alcázar de Guadalajara, de acuerdo con las recientes investigaciones ${ }^{59}$. También está presente en Granada, en el Palacio de los Abencerrajes ${ }^{60}$, y en el extremo norte del Palacio del Generalife, fruto de una reforma de principios del siglo XIV ${ }^{61}$. Un esquema similar suponemos que pudo haberse desarrollado en el lado sur del palacio levantado por Pedro I y María de Padilla en Tordesillas ${ }^{62}$, aunque su máxima expresión se alcanza sin duda

57 Navarro, Jiménez 1995:73-74.

58 Tabales 2003b, Lázaro 2004:76.

${ }^{59}$ Navarro 2006:20 y planta en p. 16; debemos resaltar de nuevo las notables dimensiones que adquieren estas salas en los palacios cristianos si las comparamos con las musulmanas, fruto sin duda del distinto modo de usar los palacios por una u otra cultura.

${ }^{60}$ Orihuela 1996:51-53.

61 Orihuela 1996:210.

62 Almagro 2005b.

Al-Qanțara (AQ) XXVIII 1, enero-junio 2007, pp. 181-228 ISSN 0211-3589 
en el Palacio de Comares, sin olvidar la combinación más elaborada del lado norte del Palacio de los Leones de la Alhambra ${ }^{63}$.

El programa desarrollado por D. Pedro en el Alcázar sevillano es sin duda de una complejidad como no se había conocido desde los tiempos del califato, cuando se construyó el Alcázar de Madinat al-Zahrā'. Pero seguramente, frente a su programa más reducido respecto al desarrollado en la ciudad palatina, se contrapone una mayor visibilidad, un sentido de la teatralidad y de la figuración del poder manifestado a través de elementos arquitectónicos cuidadosamente seleccionados y articulados. Una cuestión surge de inmediato. ¿Por qué se acudió a un repertorio formal y tipológico de raíz musulmana para materializar este ideario? Las respuestas creo que resultan obvias. En primer lugar, porque la arquitectura «cristiana» no ofrecía las soluciones espaciales y simbólicas adecuadas para este propósito. Y el ejemplo lo tenemos en el proyecto desarrollado por Alfonso X en el Cuarto del Caracol, en donde el recurso a las soluciones góticas en forma de salas longitudinales abovedadas no proporcionaban al espacio la adecuada focalidad que atendiera a los designios de resaltar la figura del monarca, mientras que el espacio de la qubba, por ejemplo, sí daba una respuesta en tal sentido. Lo mismo cabe decir respecto al valor suntuario de la decoración, que aunque realizado en materiales «pobres», conseguía efectos remarcables.

A esta primera respuesta hay que añadir otra no menos importante, pues el recurso elegido podría haber resultado contraproducente si se hubiera podido identificar como perteneciente a una cultura desconocida o considerada totalmente antagónica. Seguramente, a diferencia de lo que ocurría en el siglo XIII, a mediados de la siguiente centuria la asimilación de determinados elementos de la cultura musulmana era una realidad perfectamente asentada y los significados de la mayoría de las formas arquitectónicas islámicas estaban plenamente asumidos e integrados en el imaginario de la población del reino de Castilla, o al menos de sus élites ${ }^{64}$. En una palabra, lo que pretendemos decir es que todo este programa arquitectónico expresaba de la mejor manera posible para la época el ideario político que Pedro I pretendía imponer en el reino, y resultaba perfectamente inteligible para aquéllos a los que estaba destinado el mensaje: un rey poderoso que tenía dinero para cons-

\footnotetext{
63 Orihuela 1996:104, 113.

${ }^{64}$ Ruiz 2004:24.
}

Al-Qanțara (AQ) XXVIII 1, enero-junio 2007, pp. 181-228 ISSN 0211-3589 
truir aquel soberbio y lujoso conjunto que no admitía comparación con la residencia de ninguno de sus vasallos, y cuyo poder se visualizaba a través de los lugares en que tenía que manifestarse: el tribunal a la puerta del palacio, los diversos salones del trono y audiencias y la tribuna sobre la puerta de su residencia privada, donde podía ser contemplado por una gran multitud congregada en el patio. Todas estas formas, de innegables raíces orientales, no pudieron ser emuladas con tanta grandeza por los soberanos musulmanes de su tiempo, aunque su influjo sobre los proyectos arquitectónicos de su contemporáneo, aliado y amigo Muhammad V resultan incontestables.

\section{Bibliografía}

Almagro, A. 1999, "El Patio del Crucero del Alcázar de Sevilla", Al-Qanțara XX, 331-376.

Almagro, A. 2000, Planimetría del Alcázar de Sevilla, Granada.

Almagro, A. 2001, "La arquitectura en al-Andalus en torno al año 1000: Madinat al-Zahra", La Península Ibérica en torno al año 1000. VII Congreso de Estudios Medievales, León, 165-191.

Almagro, A. 2004, "Análisis tipológico de la arquitectura residencial de Madinat al-Zahra”, Al-Andalus und Europa zwischen Orient und Okzident, Petersberg: Michael Imhof, 117-125.

Almagro, A. 2005a, "La recuperación del jardín medieval del Patio de las Doncellas", Apuntes del Alcázar de Sevilla, 6, 44-67.

Almagro, A. 2005b, "El palacio de Pedro I en Tordesillas. Realidad e hipótesis", Reales Sitios, 163, 2-13.

Almagro, A. 2006, El Alcázar de Sevilla en el Siglo XIV. The Alcazar of Seville in the 14th Century. Audiovisual en soporte DVD, Granada: Escuela de Estudios Árabes (CSIC), Fundación El Legado Andalusí.

Cómez, R. 1996, El Alcázar del Rey D. Pedro, Sevilla.

Cómez, R. 2004, "El Alcázar de Sevilla al final de la Edad Media", Les palais dans la ville espaces urbains et lieux de la puissance publique dans la Mediterranée médiévale, Lyon.

Escribano Ucelay, V. 1972, Estudio Histórico Artístico del Alcázar de los reyes Cristianos de Córdoba, Córdoba.

Gil-Bermejo, J. 1973, "La Casa de Contratación de Sevilla (Algunos aspectos de su historia)", Anuario de Estudios Americanos, XXX, 679-761.

Jiménez, A. (Ed.) 1995, Arquitectura en al-Andalus. Documentos para el siglo XXI, Barcelona.

Jiménez, A. 1998, "La explanada de Ibn Jaldūn. Espacios civiles y religiosos de la Sevilla almohade", González Jiménez, M. Sevilla 1248, Congreso internacional Conmemorativo del 750 Aniversario de la Conquista de Sevilla por Fernando III, Rey de Castilla y León, Sevilla, pp.43-71.

Lázaro Chamorro, F. 2004, "Las torres del Infante D. Fadrique (I)", Aparejadores, 67, 71-82.

Manzano, R. 1994, La Qubba, Aula Regia en la España Musulmana, Madrid.

Al-Qanțara (AQ) XXVIII 1, enero-junio 2007, pp. 181-228 ISSN 0211-3589 
Manzano, R. 1995a, "Casas y Palacios en la Sevilla Almohade. Sus precedentes hispánicos”, Navarro, J. (ed.), Casas y palacios de al-Andalus. Siglos XII-XIII, Barcelona, 315-352.

Manzano, R. 1995b, "El Alcázar de Sevilla: Los Palacios Almohades”, Valor, M. (coor), El último siglo de la Sevilla islámica, Sevilla, 101-124.

Manzano, R. 1999, "Los palacios", Valor, M. Tahiri, A. (coor), Sevilla almohade, Sevilla-Rabat, 63-75.

Martín Fidalgo, A. El Alcázar de Sevilla bajo los Austrias.

Martín-Bueno, M. y Sáenz Preciado, J. C. 1998, "El palacio mudéjar. Introducción arqueológica”, Beltrán Martínez, A. (dir.), La Aljafería I, Zaragoza, 157-168.

Navarro Palazón, J. 1995, "Un palacio protonazarí en la Murcia del siglo XIII: Al-Qașr al-Șagir”, Navarro, J. (ed.), Casas y palacios de al-Andalus. Siglos XII-XIII, Barcelona, 315-352.

Navarro Palazón, J. y Jiménez Castillo, P. 1995, "El Castillejo de Monteagudo: Qașr ibn-Sa 'd", Navarro, J. (ed.), Casas y palacios de al-Andalus. Siglos XII-XIII, Barcelona, 63-103.

Navarro Palazón, J. 2005, "Sobre Palacios andalusíes (siglos XII-XIV)", Vivir en Palacio en la Edad Media. Siglos XII-XV, Segovia, 111-144.

Navarro Palazón, J. 2006, "El Alcázar de Guadalajara. Noticias de las excavaciones realizadas durante el año 2005”, Castillos de España, 141, III Congreso de castellología Ibérica-Apéndice. 15-23.

Orihuela, A. y López, A. C. 1990, "Una nueva interpretación del texto de Ibn al-Jațīb sobre la Alhambra de 1362", Cuadernos de la Alhambra, 26, 121-144.

Pozo Martínez, I. 1999, “Arqueología y arquitectura islámicas en el Monasterio de Santa Clara La Real (Murcia)”, Paraísos perdidos. Patios y claustros, Murcia, 53-104.

Ruiz Souza, J. C., "Castilla y Al-Andalus. Arquitecturas aljamiadas y otros grados de asimilación”, Anuario del departamento de Historia y Teoría del Arte (UAM), XVI, 17-43.

Tabales, M. A. 2000, “Investigaciones arqueológicas en el Real Alcázar de Sevilla. Notas sobre evolución constructiva y espacial", Apuntes del Alcázar de Sevilla, 1, 12-45.

Tabales, M. A. 2001a, "El palacio islámico localizado bajo el patio de la Montería del Alcázar de Sevilla”, Anuario Arqueológico de Andalucía 1997, 224-241.

Tabales, M. A. 2001b, "Las murallas del Alcázar de Sevilla. Investigaciones arqueológicas en los recintos islámicos", Apuntes del Alcázar de Sevilla, 2, 7-35.

Tabales, M. A. 2002, El Alcázar de Sevilla. Primeros estudios sobre estratigrafía y evolución constructiva, Sevilla.

Tabales, M. A. 2003a, "Investigaciones arqueológicas en el Patio de las Doncellas", Apuntes del Alcázar de Sevilla, 4, 7-25.

Tabales, M. A. 2003b, Excavaciones en el convento de Santa Clara de Sevilla, Fase I (Memoria inédita depositada en la Dirección General de Bienes Culturales de la Junta de Andalucía).

Tabales, M. A. 2006, "Investigaciones arqueológicas en el Patio del León”, Apuntes del Alcázar de Sevilla, 7, 6-39.

Tubino, F. M. 1886, El Alcázar de Sevilla, Sevilla (reedición 1999).

Valor, M. 1991, La arquitectura militar y palatina en la Sevilla musulmana, Sevilla.

Vigil-Escalera, M. 1992, El jardín musulmán de la antigua Casa de Contratación de Sevilla, Intervención arquitectónica, Sevilla (reedición 1998).

Vigil-Escalera, M. 2004, "Un prototipo sevillano de jardín islámico", Aparejadores, 67, 64-70.

Al-Qanțara (AQ) XXVIII 1, enero-junio 2007, pp. 181-228 ISSN 0211-3589 


\section{Anexo 1}

Figura 1.-Planta actual del patio de la antigua Casa de Contratación

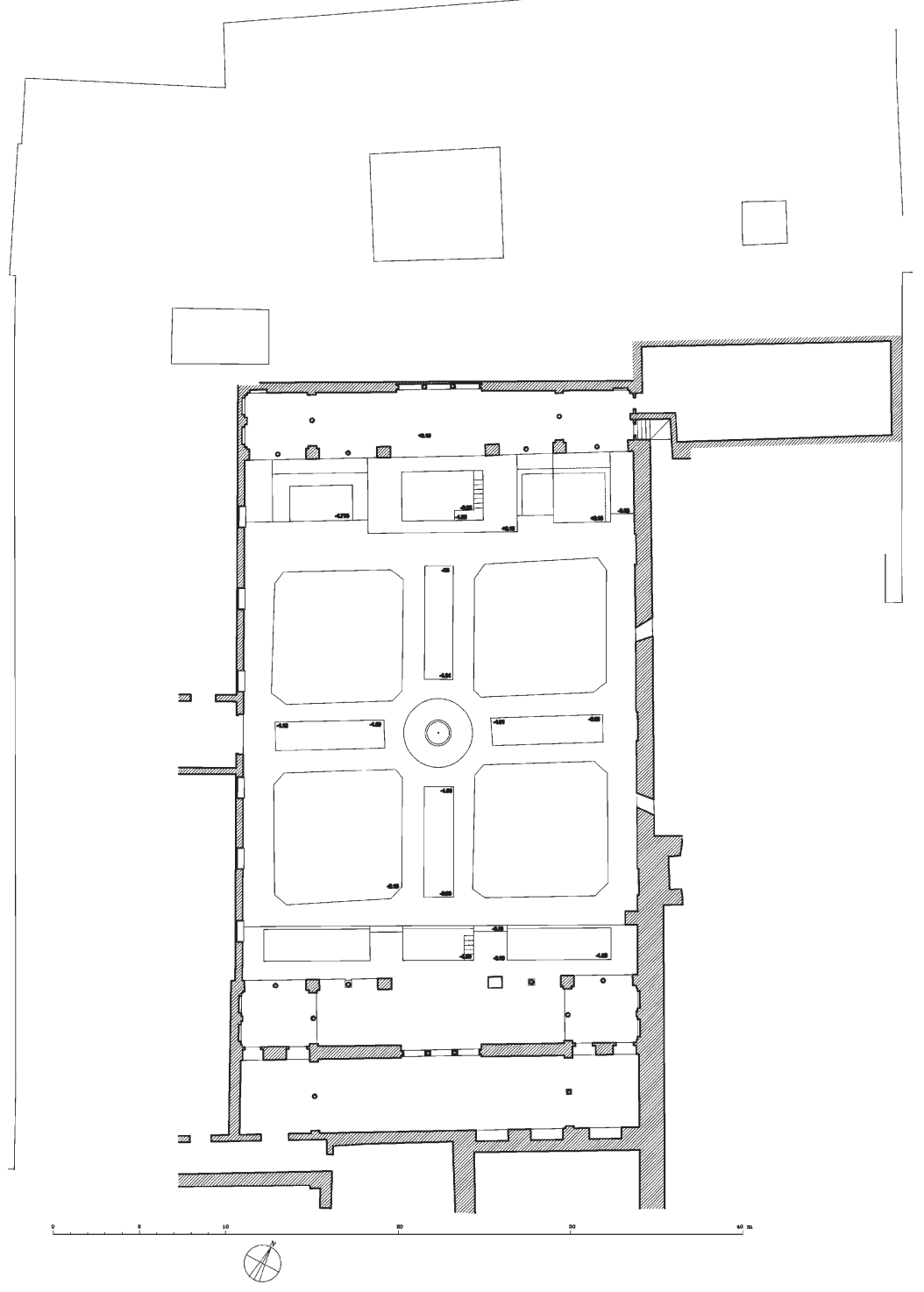

Al-Qanțara (AQ) XXVIII 1, enero-junio 2007, pp. 181-228 ISSN 0211-3589 
Figura 2.- -Vista general del patio de la antigua Casa de Contratación

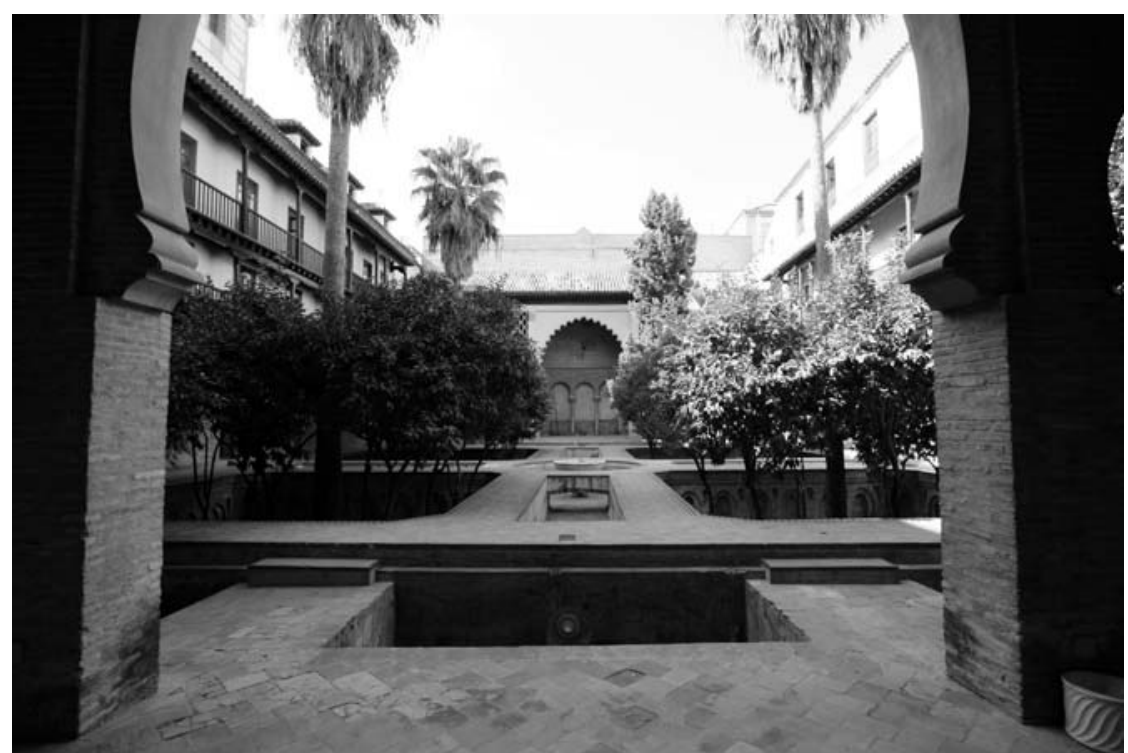

Al-Qanțara (AQ) XXVIII 1, enero-junio 2007, pp. 181-228 ISSN 0211-3589 
FIgURA 3.-Planta hipotética del patio en época almohade

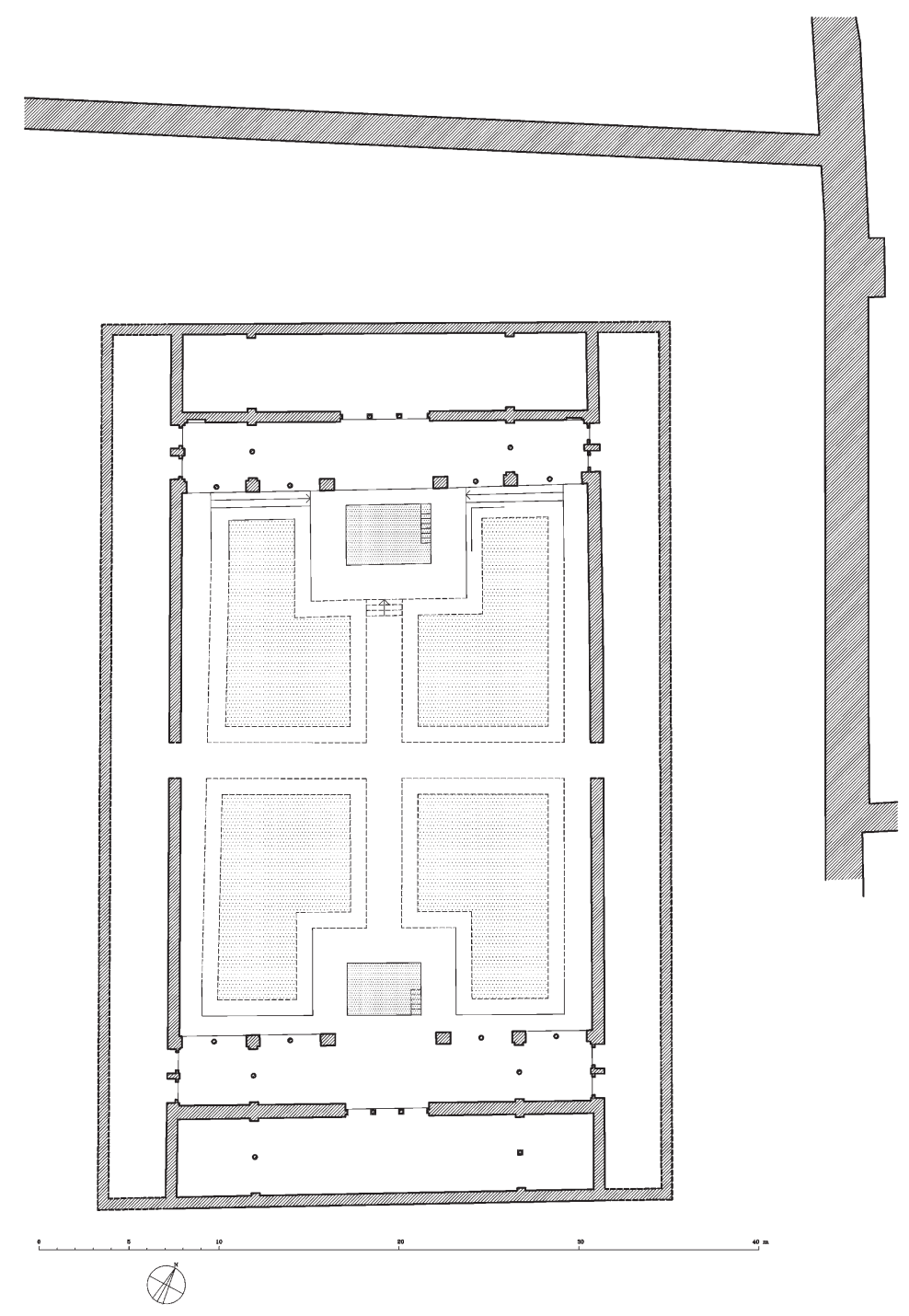

Al-Qanțara (AQ) XXVIII 1, enero-junio 2007, pp. 181-228 ISSN 0211-3589 
FIGURA 4.- Alzado norte del patio en época almohade

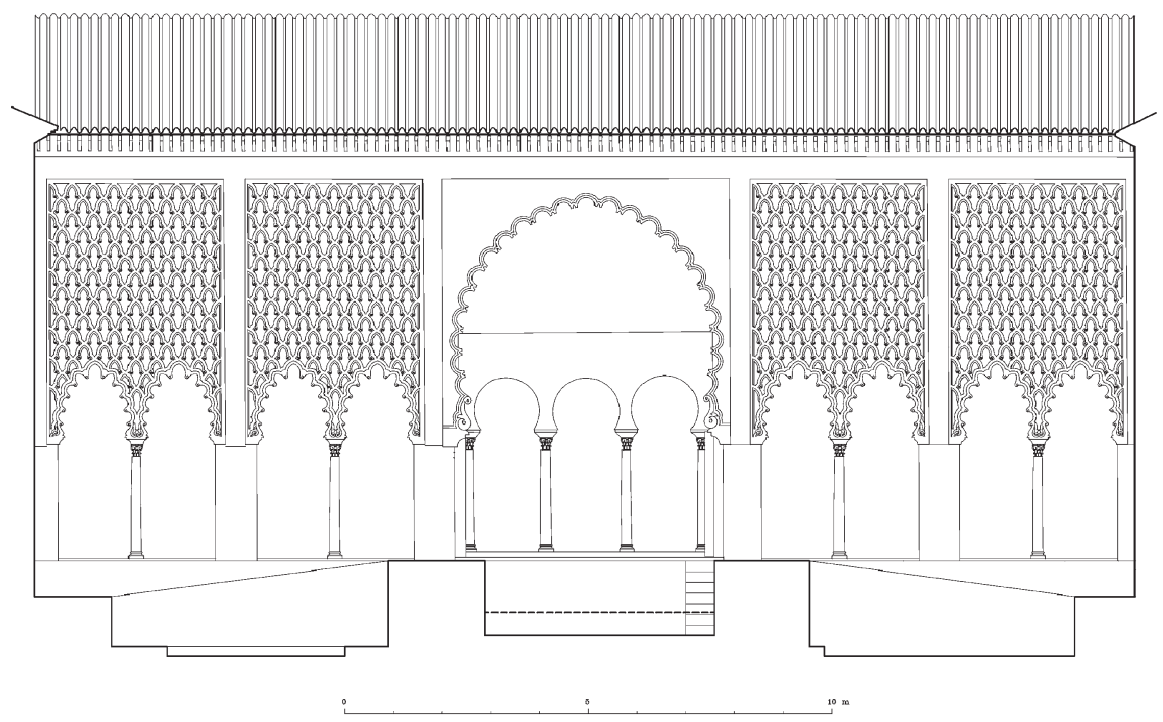

FIGURA 5.- Vista del pórtico almohade septentrional

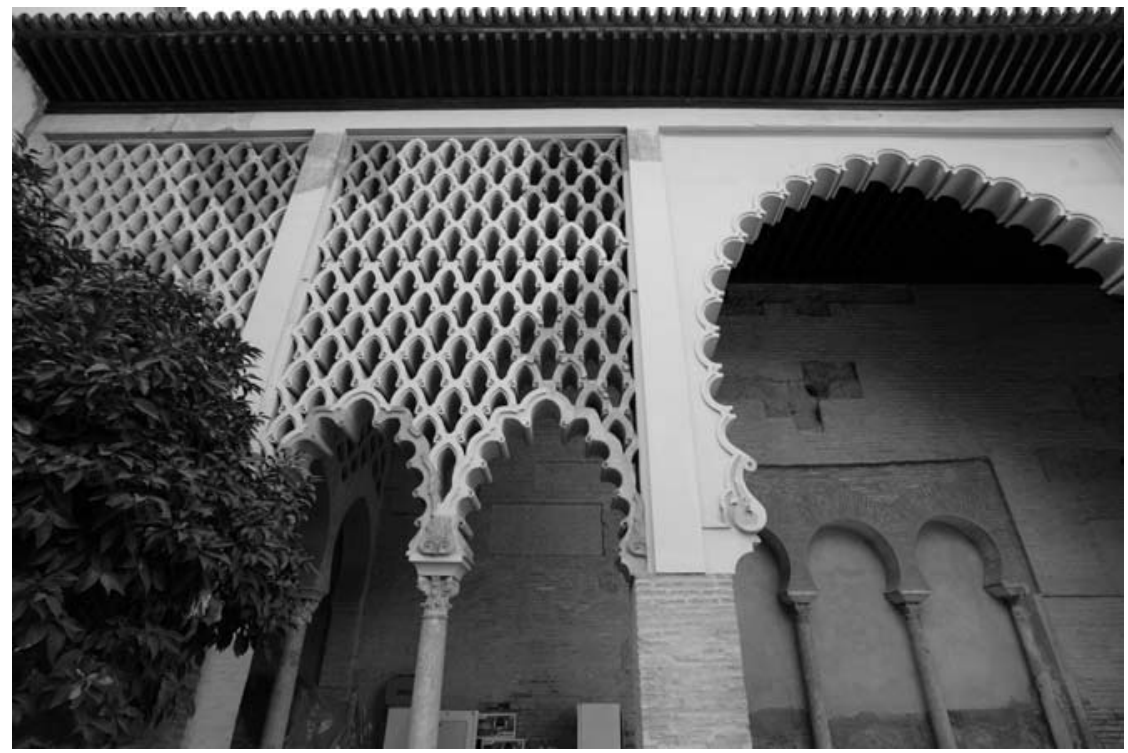

Al-Qanțara (AQ) XXVIII 1, enero-junio 2007, pp. 181-228 ISSN 0211-3589 
FIGURA 6.-Vista de los andenes y rampas del jardín almohade

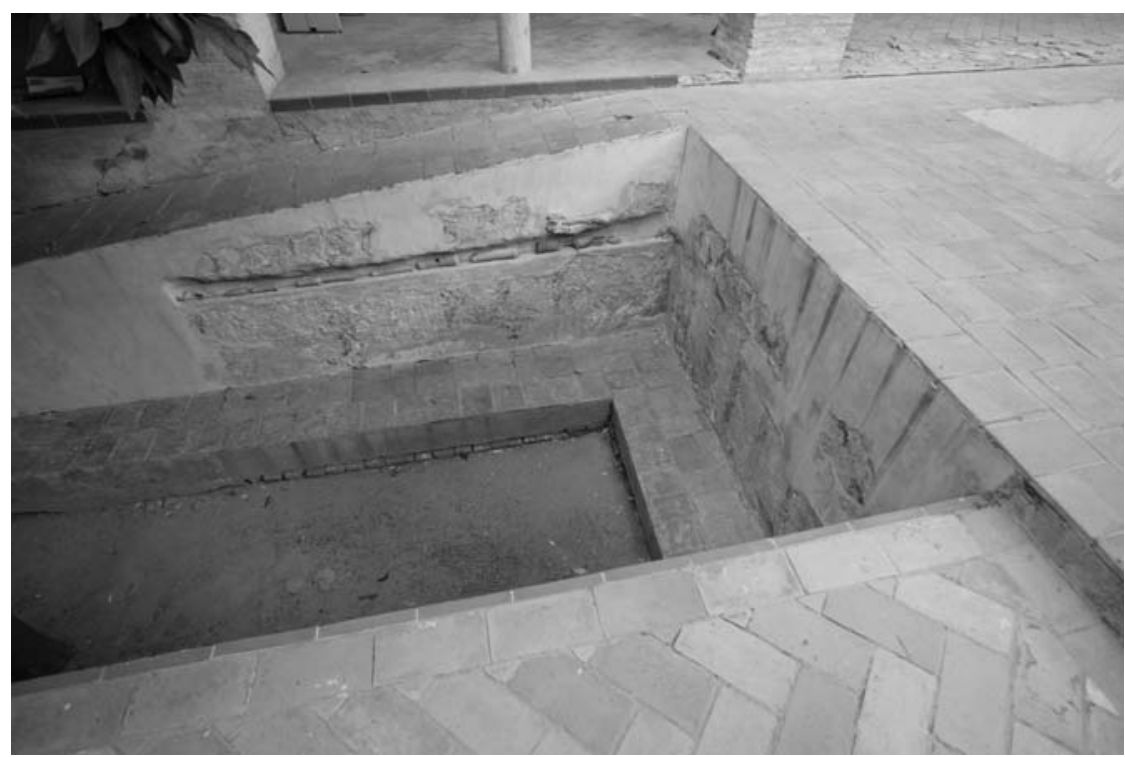

FiguRA 7.-Reconstrucción virtual del patio en época almohade

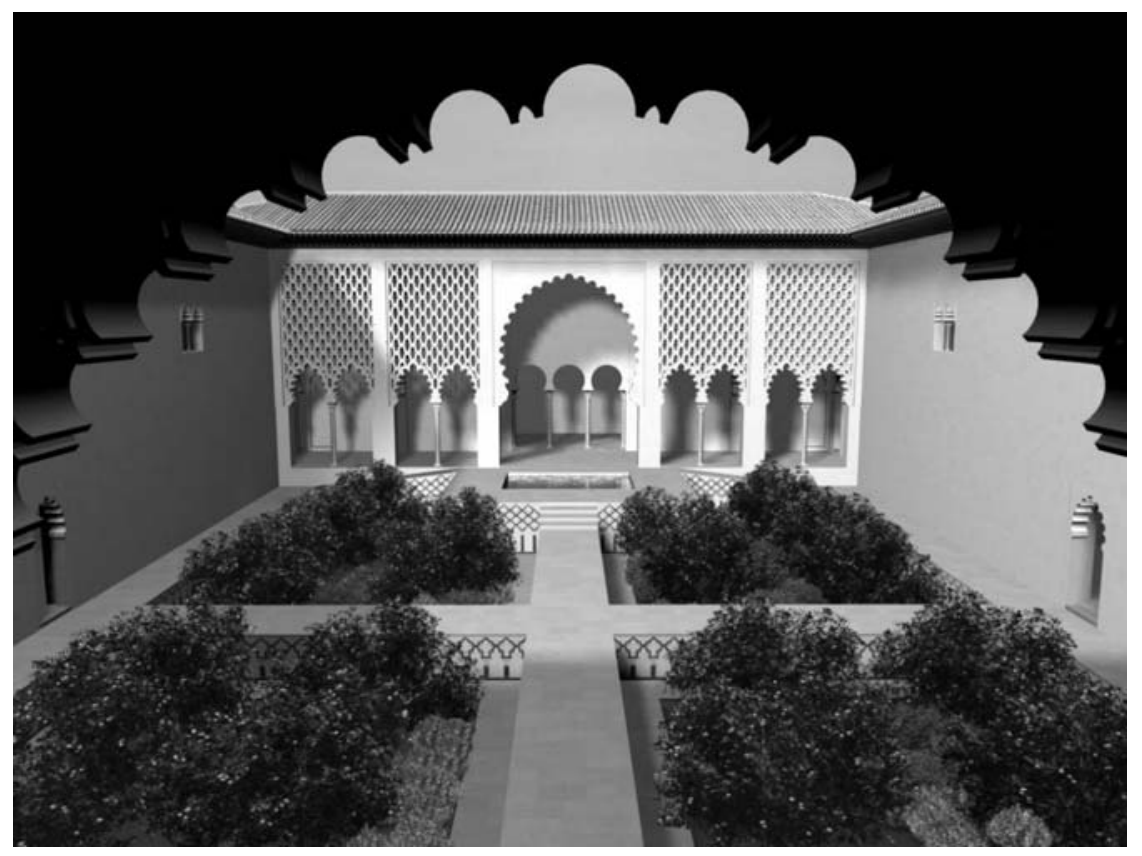

Al-Qanțara (AQ) XXVIII 1, enero-junio 2007, pp. 181-228 ISSN 0211-3589 
FIgURA 8.-Reconstrucción virtual del patio en época almohade

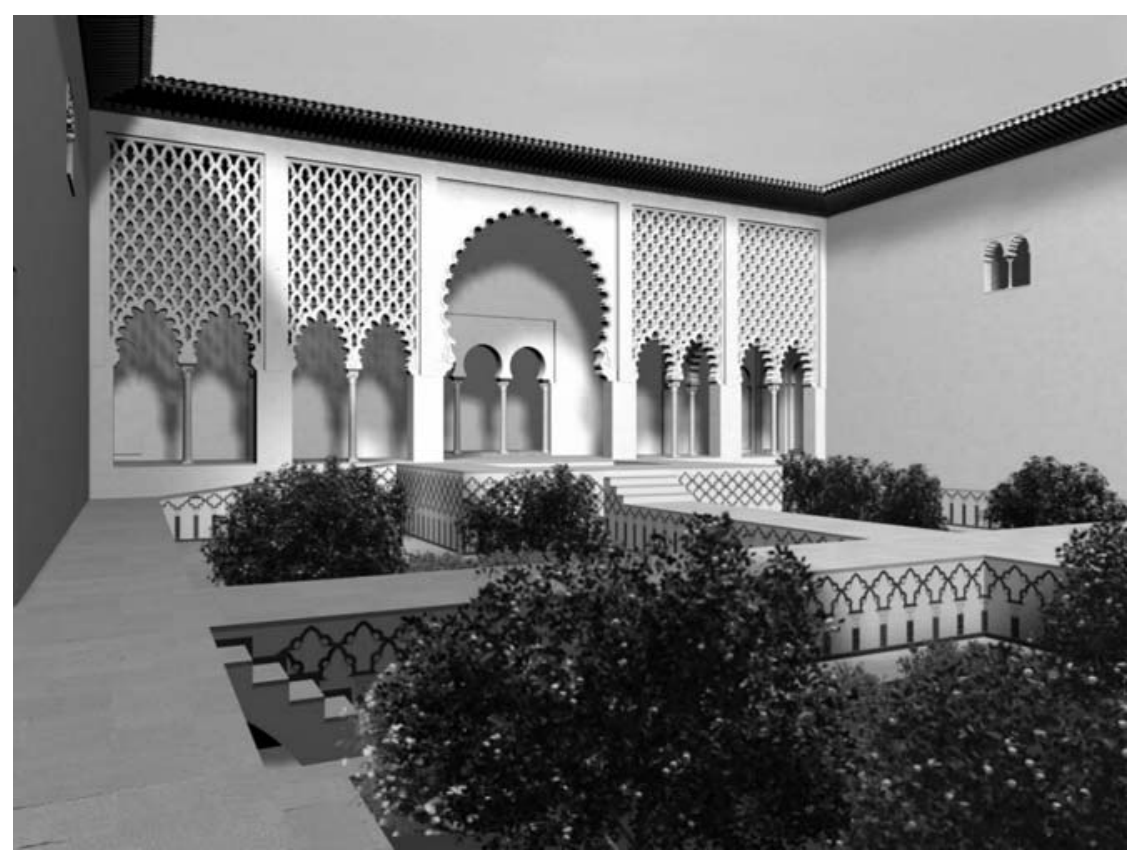

Al-Qantara (AQ) XXVIII 1, enero-junio 2007, pp. 181-228 ISSN 0211-3589 
FigURA 9.-Planta hipotética del patio tras la reforma cristiana

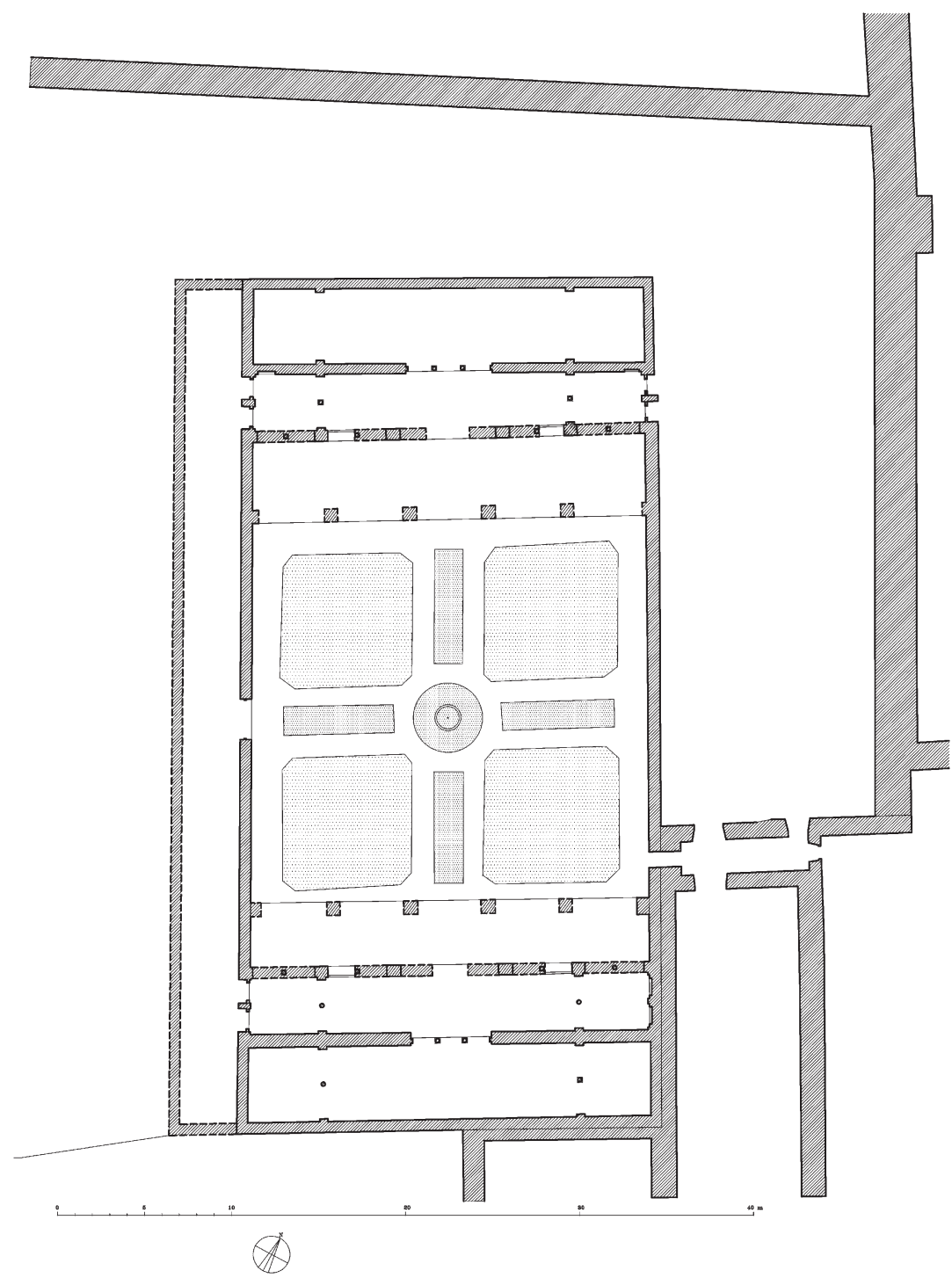

Al-Qanțara (AQ) XXVIII 1, enero-junio 2007, pp. 181-228 ISSN 0211-3589 
Figura 10.- Alzado hipotético del lado norte del patio tras la reforma cristiana

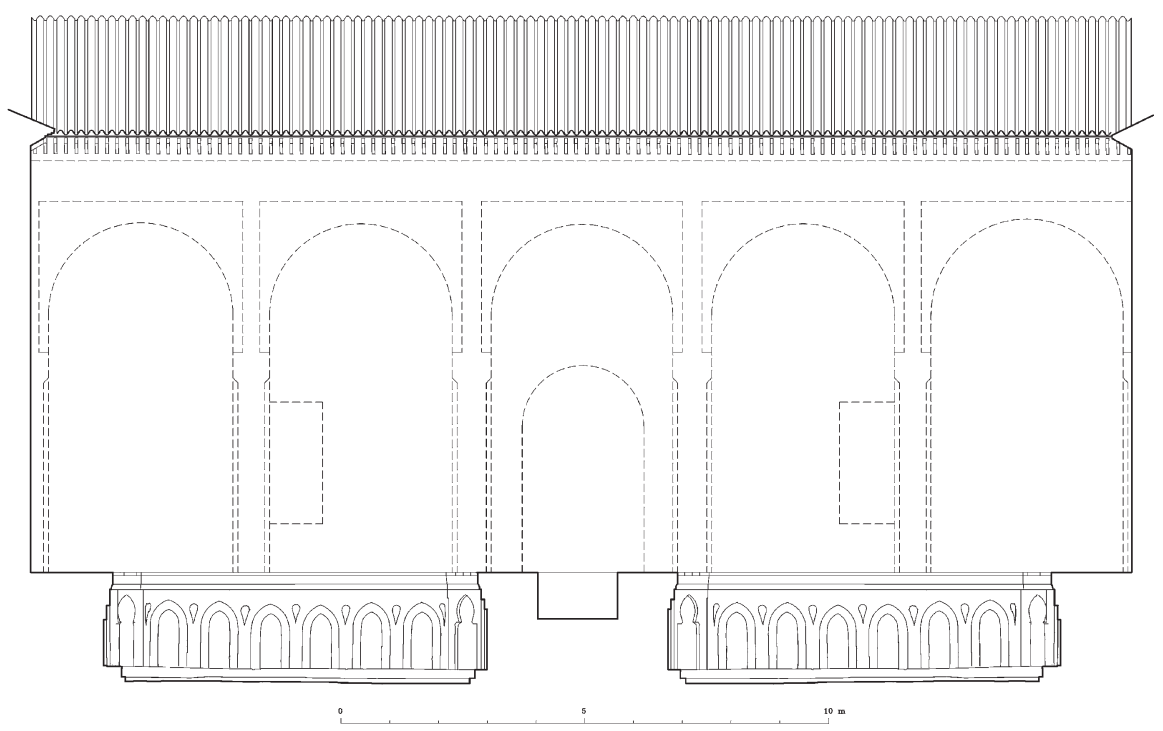

Figura 11.-- La alberca central del jardín cristiano

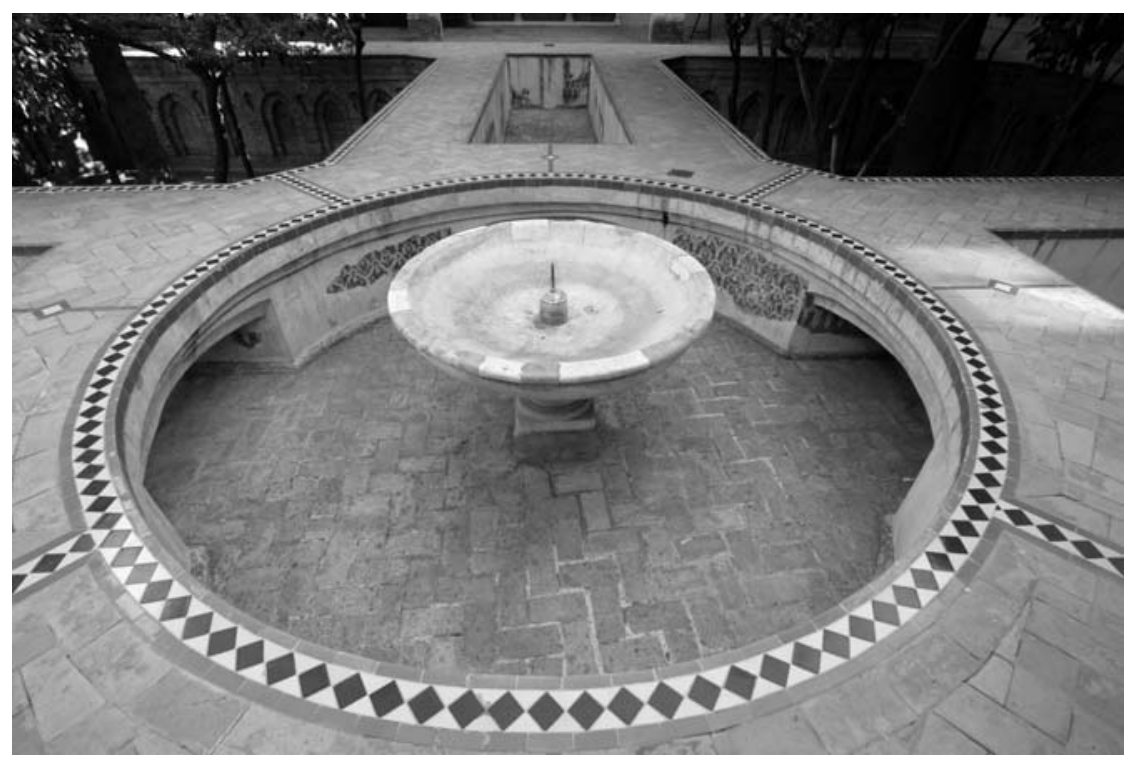

Al-Qanțara (AQ) XXVIII 1, enero-junio 2007, pp. 181-228 ISSN 0211-3589 
FIgURA 12.-Vista de uno de los parterres del jardín cristiano

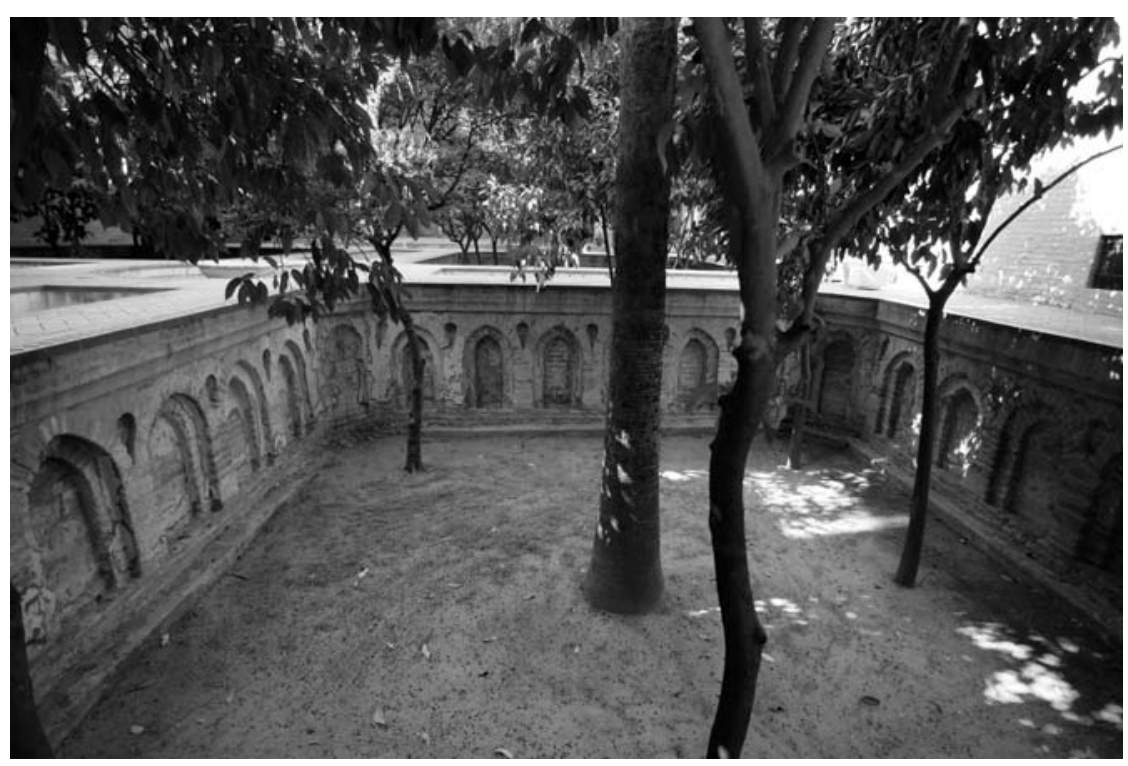

FIGURA 13.-Decoración pictórica de la alberca central de época cristiana

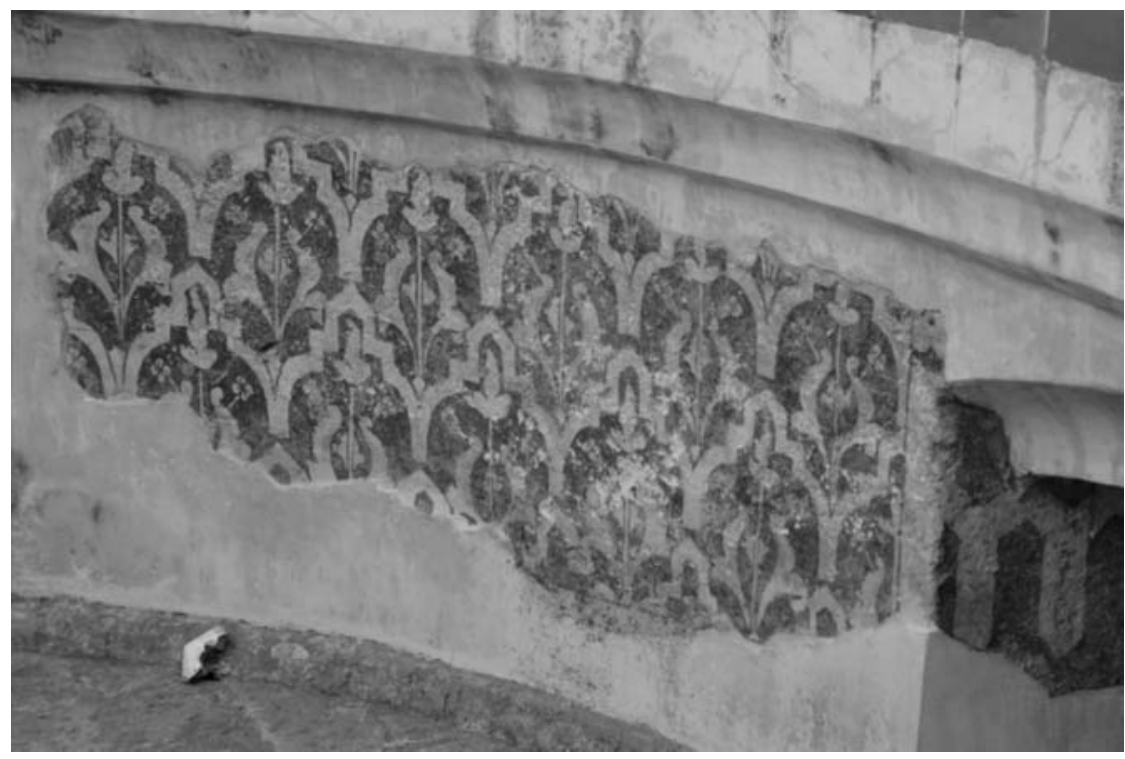

Al-Qanțara (AQ) XXVIII 1, enero-junio 2007, pp. 181-228 ISSN 0211-3589 
FIGURA 14.- Reconstrucción virtual del patio tras la reforma cristiana

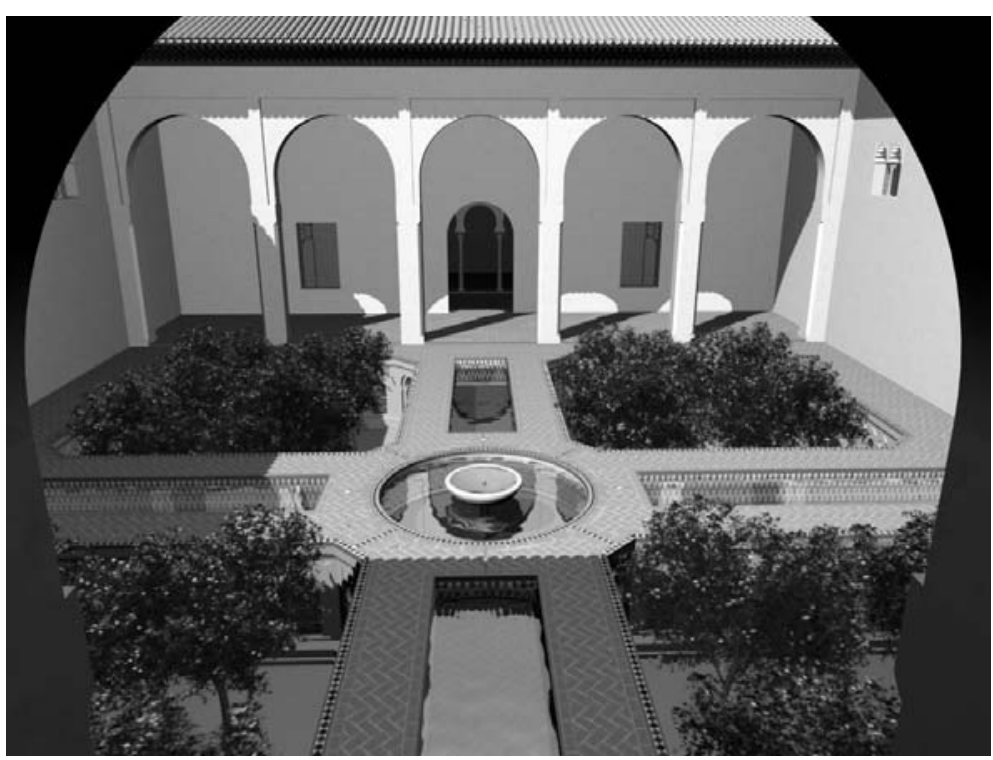

FIGURA 15.-Reconstrucción virtual del patio tras la reforma cristiana

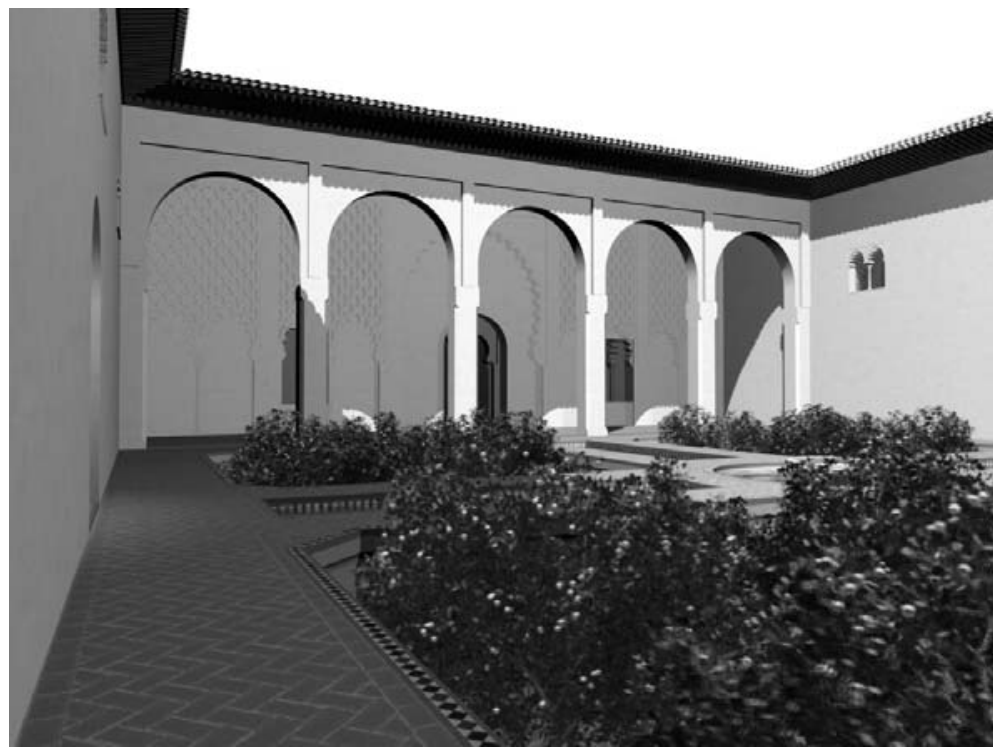

Al-Qanțara (AQ) XXVIII 1, enero-junio 2007, pp. 181-228 ISSN 0211-3589 
Figura 16.-Planta hipotética de la Casa de Contratación

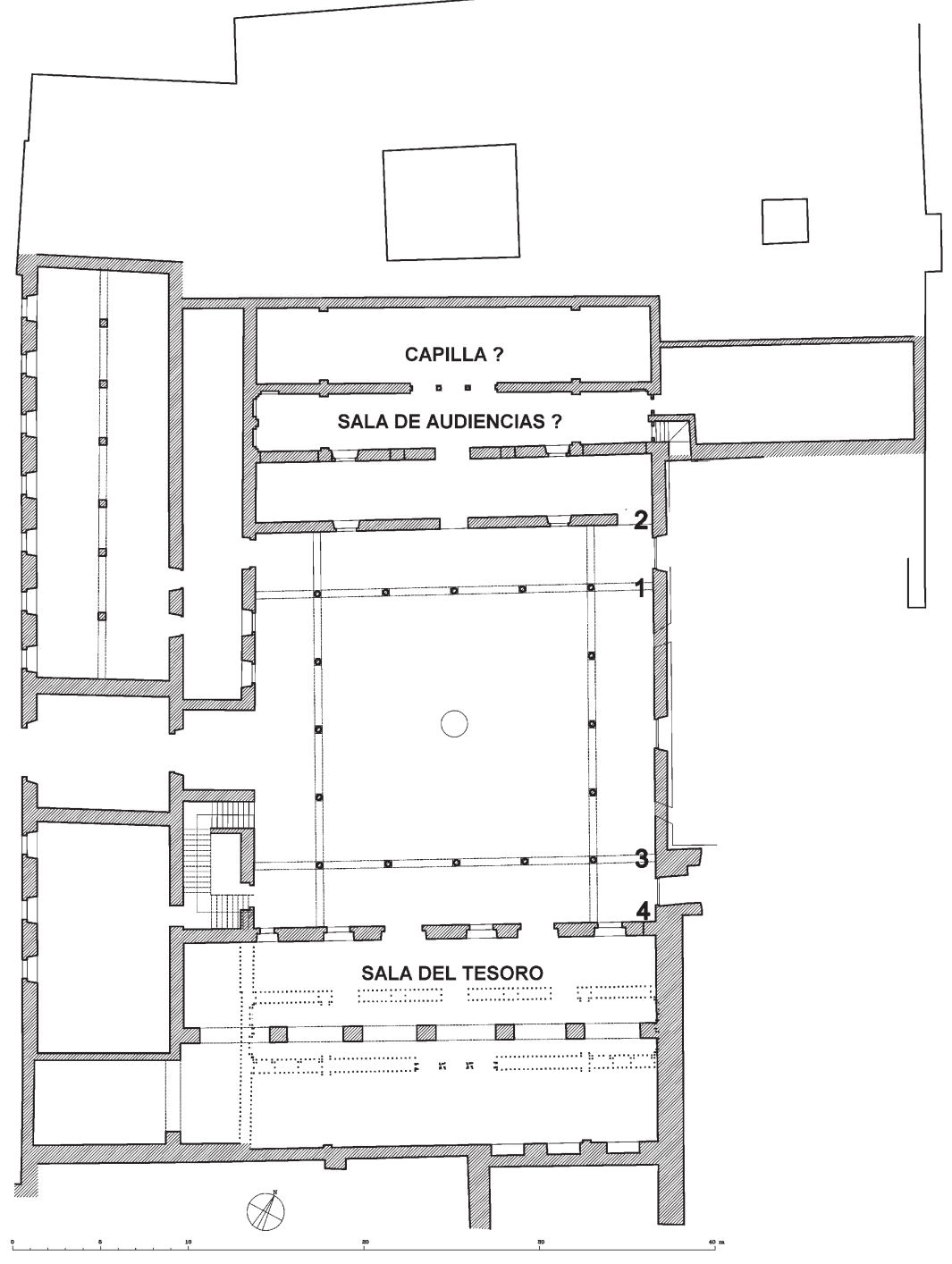

Al-Qanțara (AQ) XXVIII 1, enero-junio 2007, pp. 181-228 ISSN 0211-3589 
Figura 17.- Restos de las impostas de los arcos del patio de la Casa de Contratación correspondientes a los números 2 y 1 de la Fig. 16

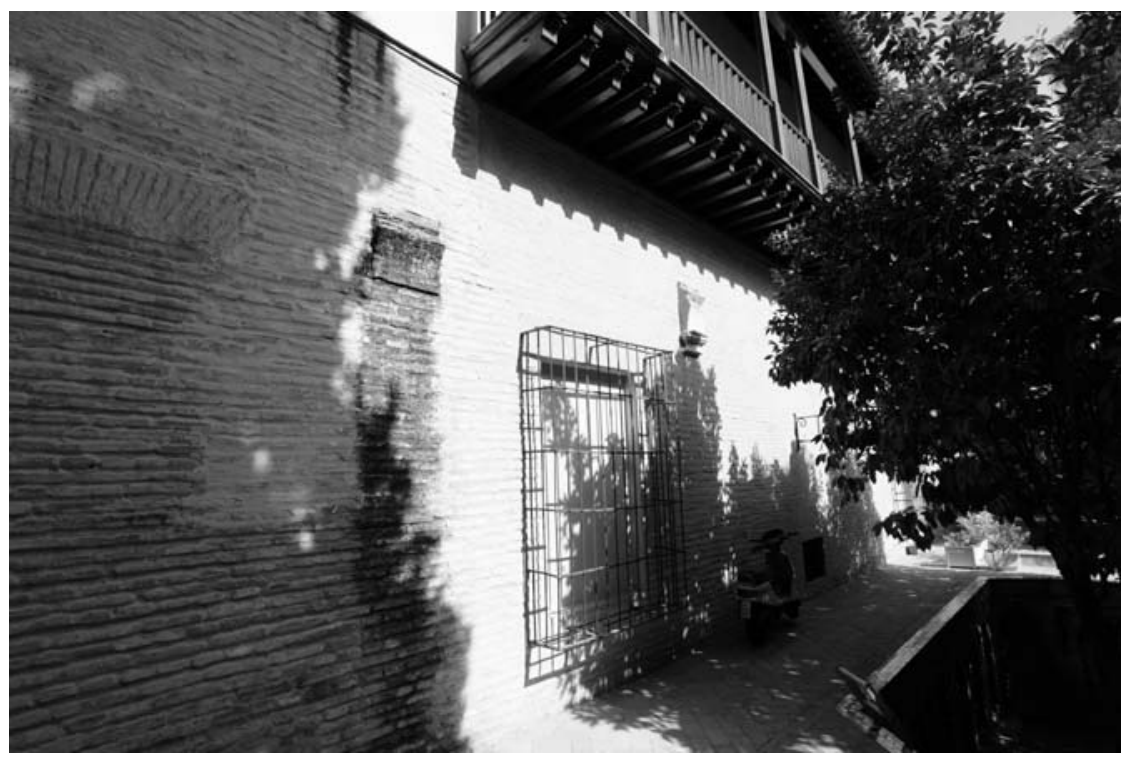

Al-Qanțara (AQ) XXVIII 1, enero-junio 2007, pp. 181-228 ISSN 0211-3589 
Figura 18.-Planta de la Casa de Contratación según el plano de 1834

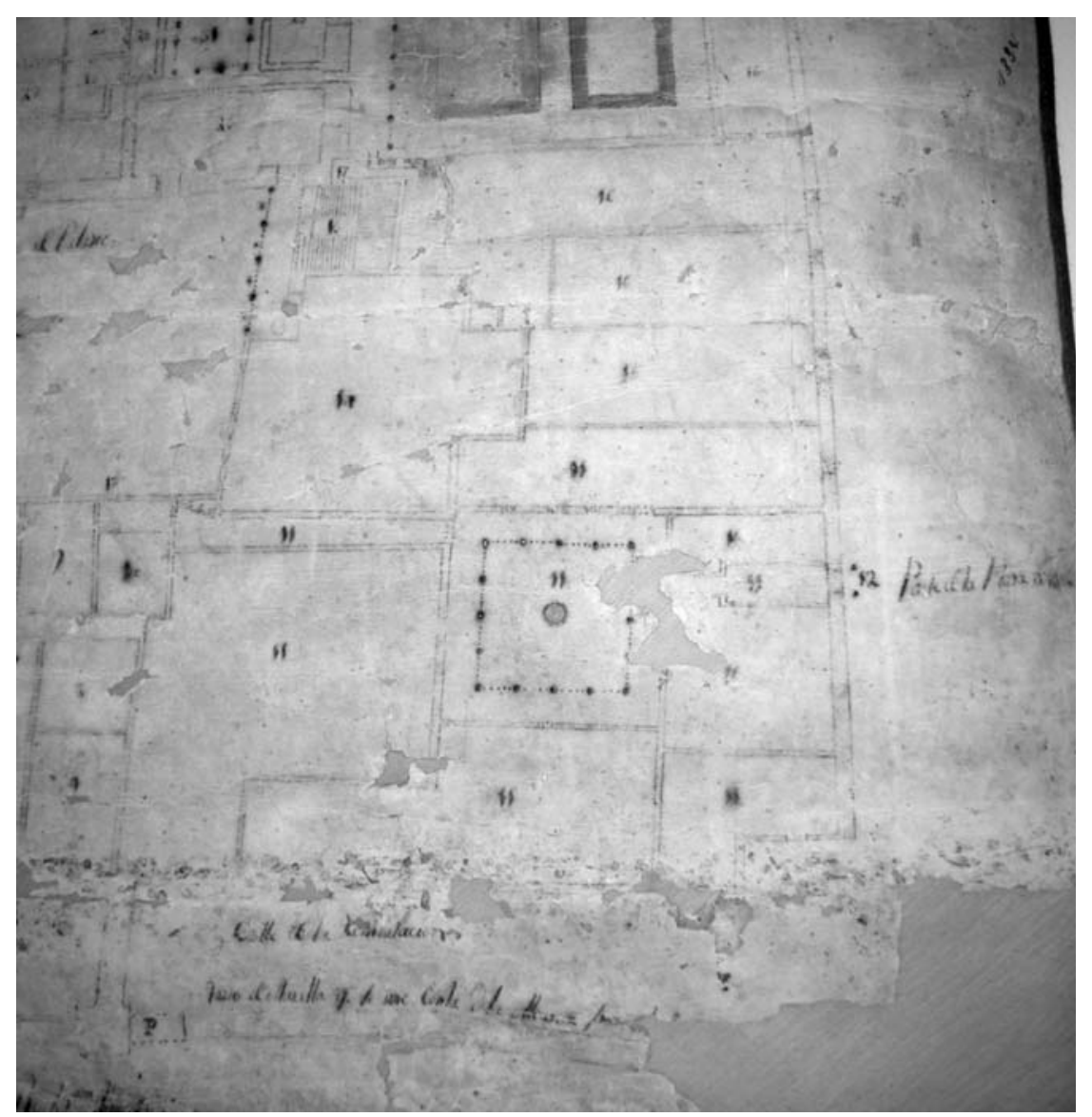

Al-Qanțara (AQ) XXVIII 1, enero-junio 2007, pp. 181-228 ISSN 0211-3589 
Figura 19.-Planta de la Casa de Contratación según el plano de J. Fernández de 1872. (C) Patrimonio Nacional

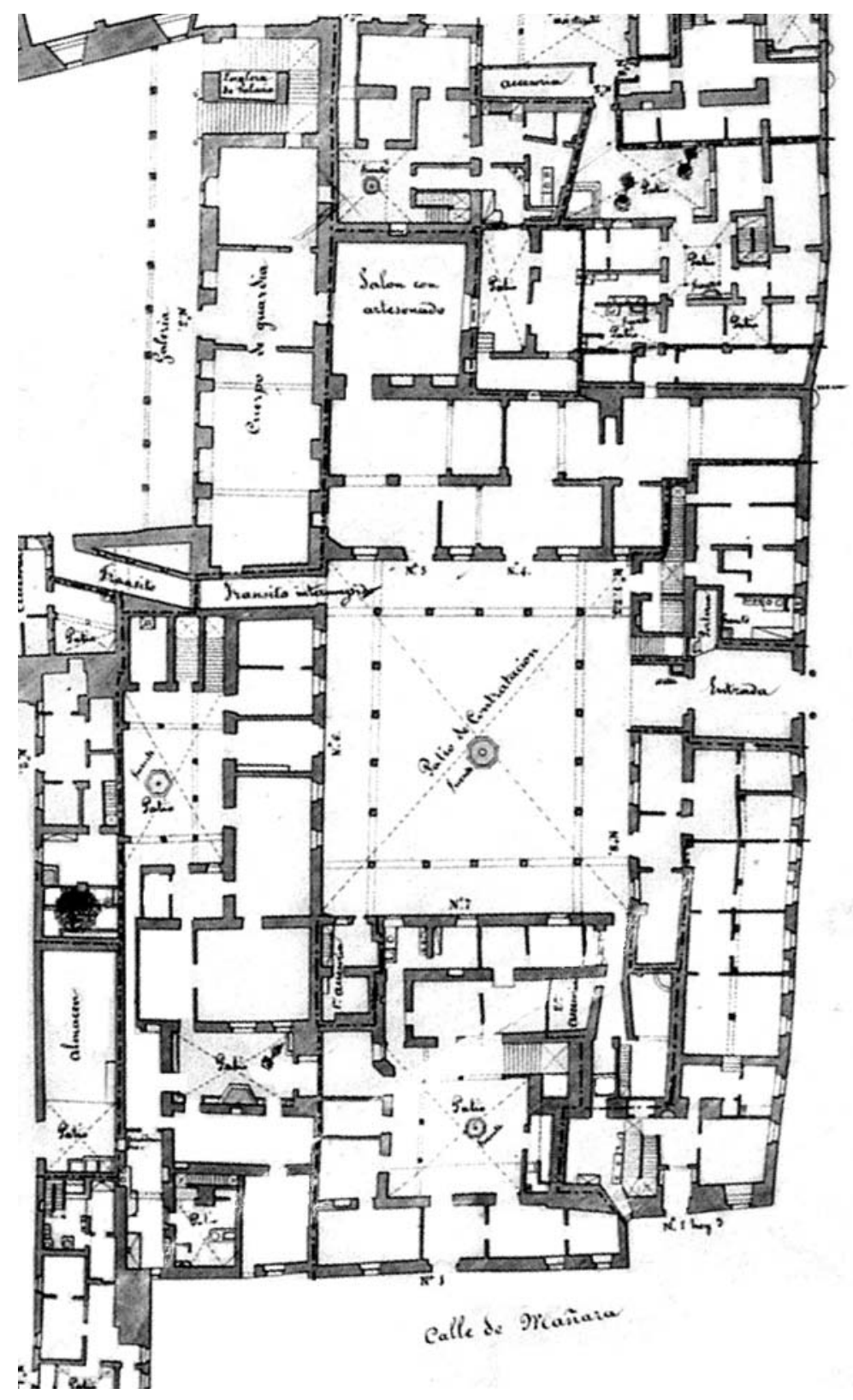

Al-Qanțara (AQ) XXVIII 1, enero-junio 2007, pp. 181-228 ISSN 0211-3589 
Figura 20.- Puerta de la Montería con los dos arcos laterales, en sus orígenes ciegos. Se aprecia al fondo la fachada del palacio de Pedro I

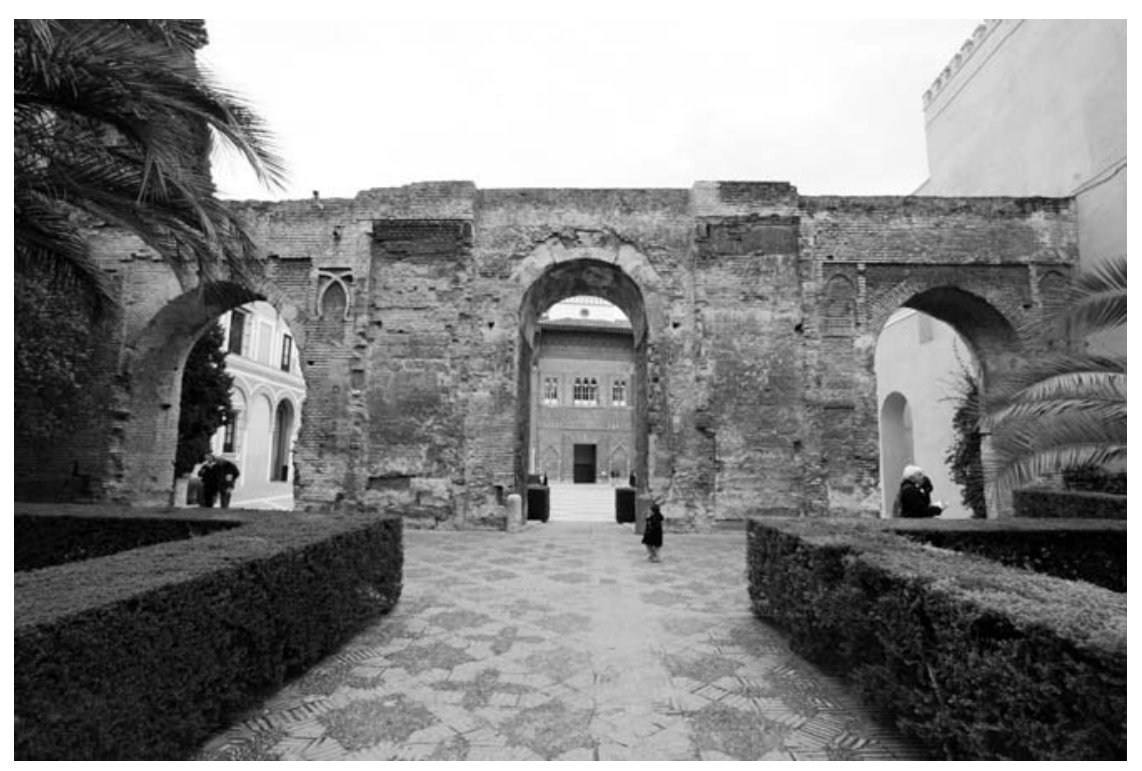

Al-Qanțara (AQ) XXVIII 1, enero-junio 2007, pp. 181-228 ISSN 0211-3589 
Figura 21.- - Lado sur del patio de la casa de Contratación durante las obras de restauración. Se aprecia detrás el volumen de la gran qubba proyectada en tiempos de Pedro I

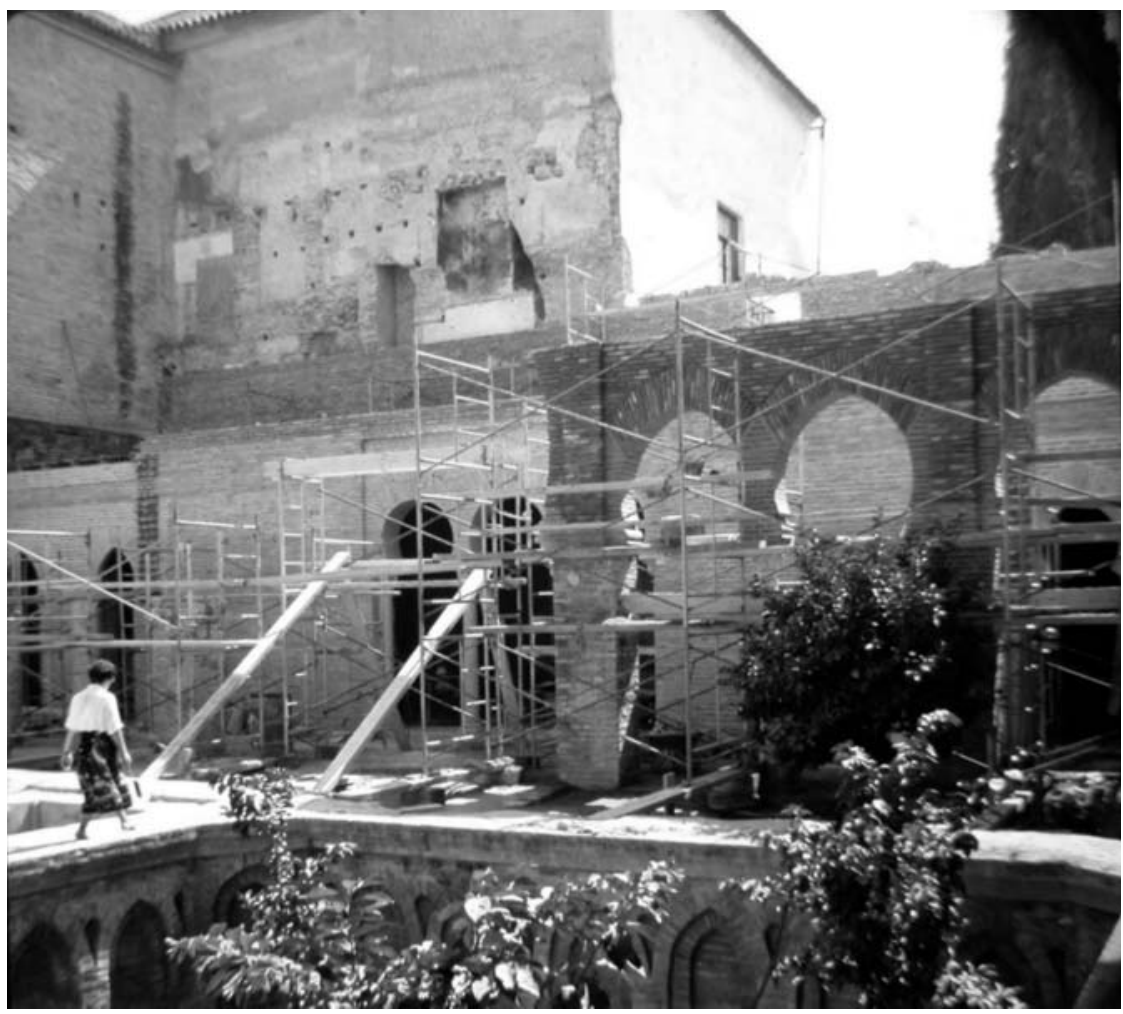

Al-Qanțara (AQ) XXVIII 1, enero-junio 2007, pp. 181-228 ISSN 0211-3589 
FIgURA 22.--Detalle de la planta del Alcázar de Sevilla atribuida a Vermondo Resta, de hacia 1608

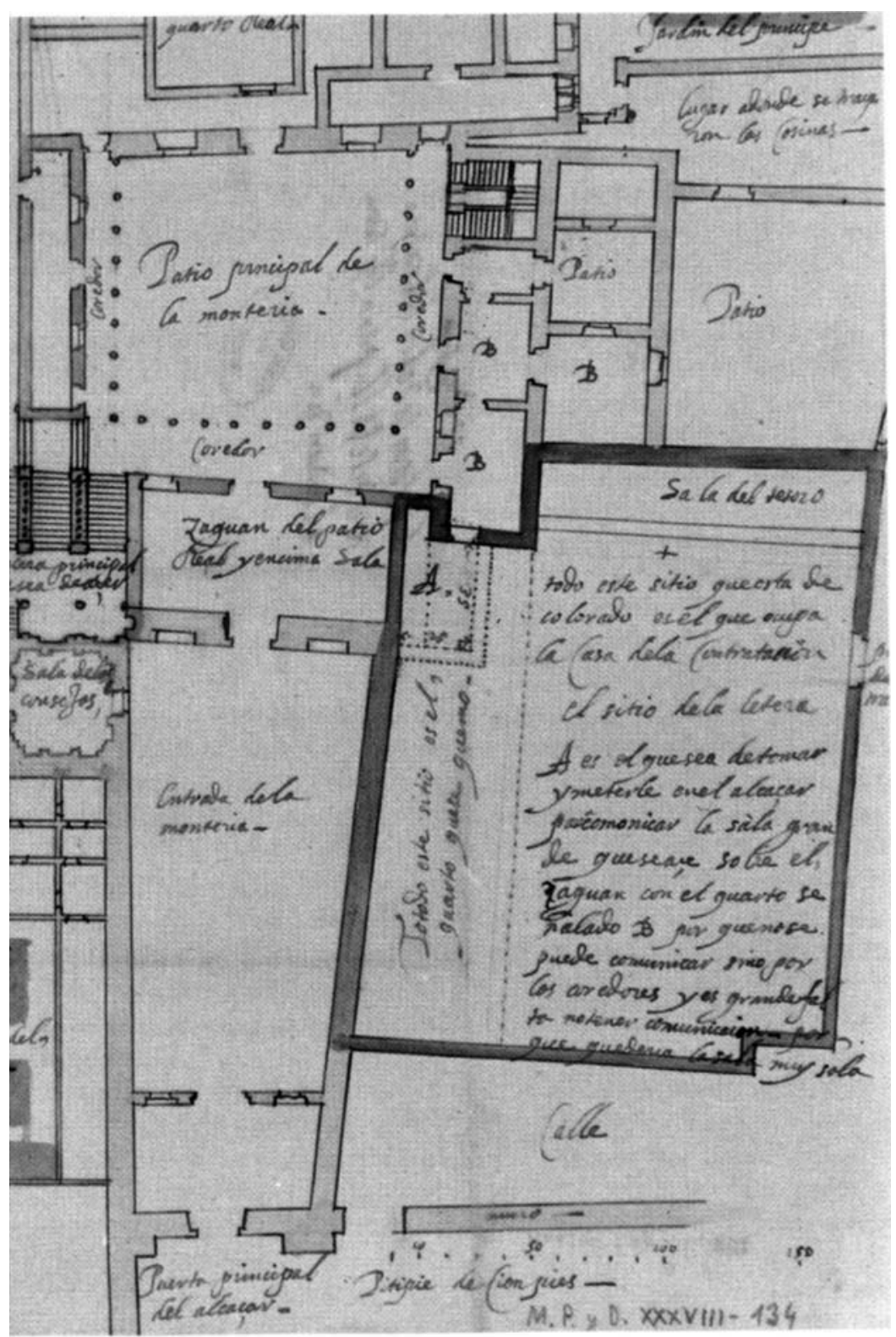

Al-Qanțara (AQ) XXVIII 1, enero-junio 2007, pp. 181-228 ISSN 0211-3589 
Figura 23.-Detalle de la planta del Alcázar de Sevilla de Sebastián van der Borcht de 1759

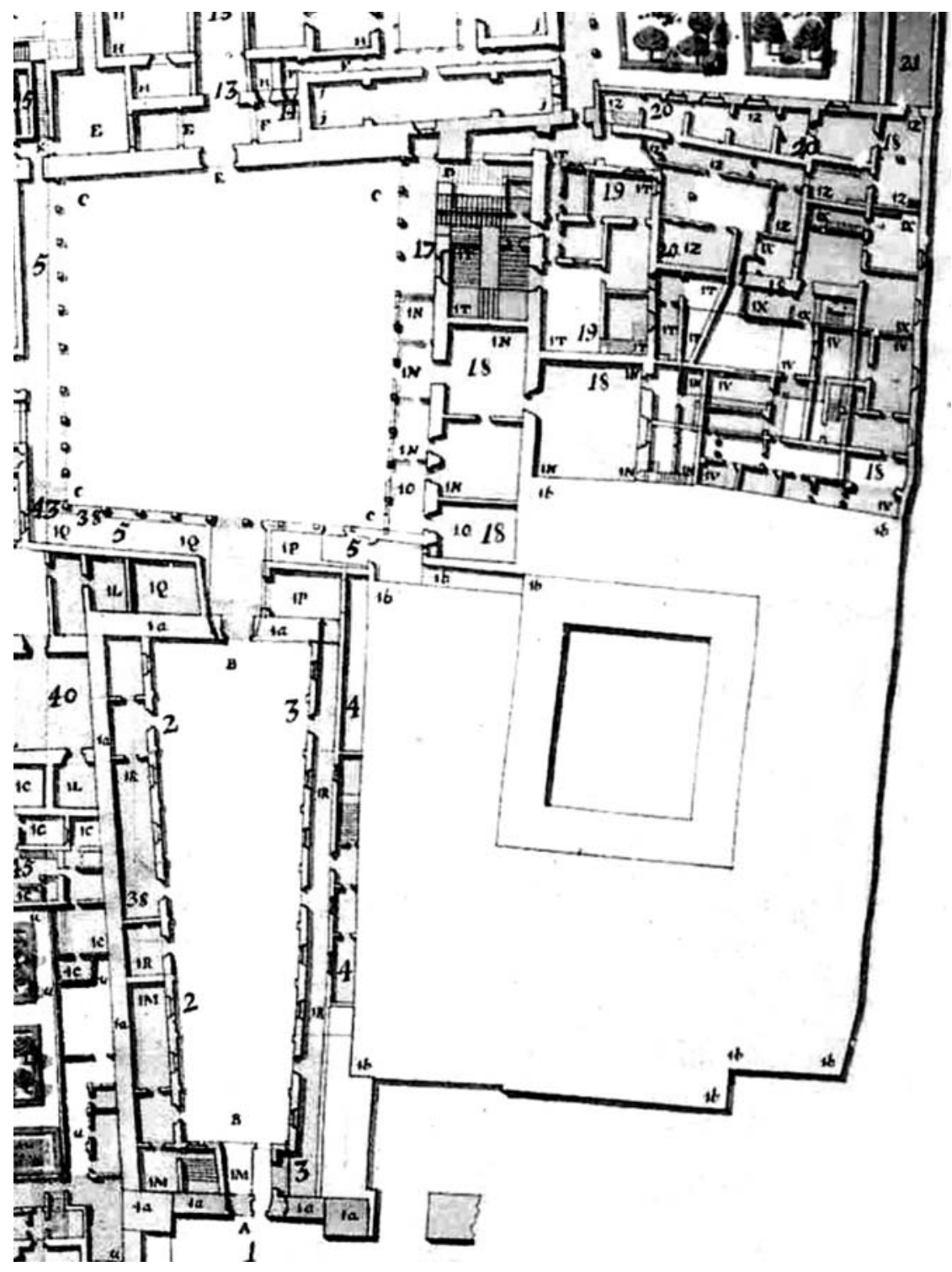


Figura 24.-Planta hipotética del Alcázar de Sevilla con el proyecto arquitectónico de Pedro I. 1.- Puerta del León. 2.- Puerta de la Montería. 3.- Patio de la Montería. 4.- Cuarto del Yeso. 5.- Sala del Consejo o de la Justicia. 6.- Patio del Crucero. 7.- Cuarto del Caracol. 8.- Cuarto Real. 9.- Cuarto de la Montería. 10.- Cuarto de los Cuatro Palacios? (Casa de Contratación)

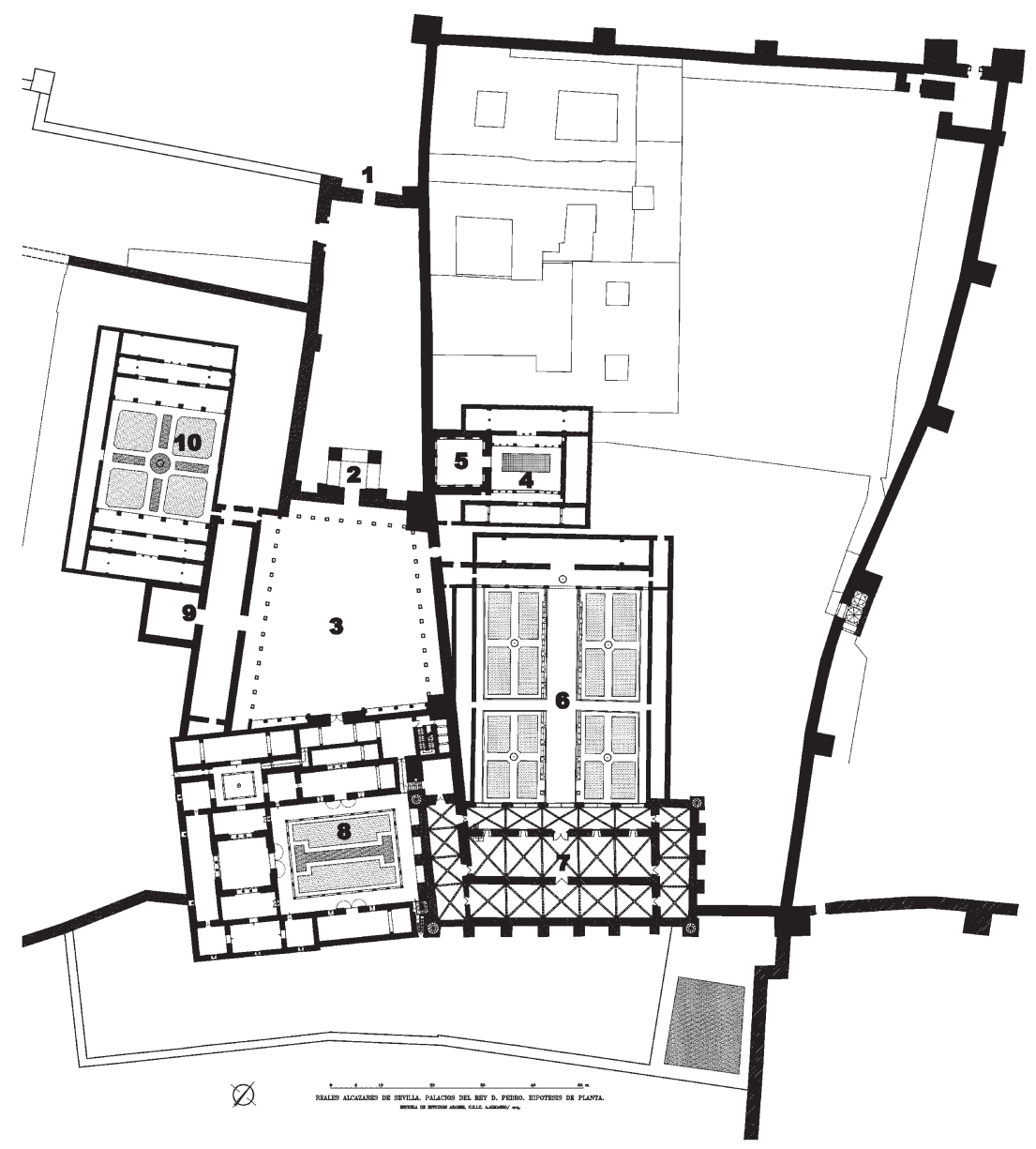

Recibido: $17 / 03 / 05$

Aceptado: 29/06/06

Al-Qanțara (AQ) XXVIII 1, enero-junio 2007, pp. 181-228 ISSN 0211-3589 